\title{
Genomic characterization of the Yersinia genus
}

\author{
Peter E Chen ${ }^{1 \dagger}$, Christopher Cook ${ }^{1 \dagger}$, Andrew C Stewart ${ }^{1 \dagger}$, Niranjan Nagarajan ${ }^{2,7}$, Dan D Sommer $^{2}$, Mihai Pop ${ }^{2}$, \\ Brendan Thomason", Maureen P Kiley Thomason', Shannon Lentz ${ }^{1}$, Nichole Nolan', Shanmuga Sozhamannan', \\ Alexander Sulakvelidze ${ }^{3}$, Alfred Mateczun', Lei Du', Michael E Zwick ${ }^{1,5}$, Timothy D Read ${ }^{1,5,6^{*}}$
}

\begin{abstract}
Background: New DNA sequencing technologies have enabled detailed comparative genomic analyses of entire genera of bacterial pathogens. Prior to this study, three species of the enterobacterial genus Yersinia that cause invasive human diseases (Yersinia pestis, Yersinia pseudotuberculosis, and Yersinia enterocolitica) had been sequenced. However, there were no genomic data on the Yersinia species with more limited virulence potential, frequently found in soil and water environments.

Results: We used high-throughput sequencing-by-synthesis instruments to obtain 25- to 42-fold average redundancy, whole-genome shotgun data from the type strains of eight species: Y. aldovae, Y. bercovieri, $Y$. frederiksenii, Y. kristensenii, Y. intermedia, Y. mollaretii, Y. rohdei, and Y. ruckeri. The deepest branching species in the genus, Y. ruckeri, causative agent of red mouth disease in fish, has the smallest genome (3.7 Mb), although it shares the same core set of approximately 2,500 genes as the other members of the species, whose genomes range in size from 4.3 to $4.8 \mathrm{Mb}$. Yersinia genomes had a similar global partition of protein functions, as measured by the distribution of Cluster of Orthologous Groups families. Genome to genome variation in islands with genes encoding functions such as ureases, hydrogeneases and B-12 cofactor metabolite reactions may reflect adaptations to colonizing specific host habitats.

Conclusions: Rapid high-quality draft sequencing was used successfully to compare pathogenic and nonpathogenic members of the Yersinia genus. This work underscores the importance of the acquisition of horizontally transferred genes in the evolution of $Y$. pestis and points to virulence determinants that have been gained and lost on multiple occasions in the history of the genus.
\end{abstract}

\section{Background}

Of the millions of species of bacteria that live on this planet, only a very small percentage cause serious human diseases [1]. Comparative genetic studies are revealing that many pathogens have only recently emerged from protean environmental, commensal or zoonotic populations [2-5]. For a variety of reasons, most research effort has been focused on characterizing these pathogens, while their closely related non-pathogenic relatives have only been lightly studied. As a result, our understanding of the population biology of these clades remains biased, limiting our knowledge of the evolution of virulence and our ability to design

\footnotetext{
* Correspondence: tread@emory.edu

† Contributed equally

${ }^{1}$ Biological Defense Research Directorate, Naval Medical Research Center, 503 Robert Grant Avenue, Silver Spring, Maryland 20910, USA
}

reliable assays that distinguish pathogen signatures from the background in the clinic and environment [6].

The recent development of second generation sequencing platforms (reviewed by Mardis $[7,8]$ and Shendure $[7,8]$ ) offers an opportunity to change the direction of microbial genomics, enabling the rapid genome sequencing of large numbers of strains of both pathogenic and non-pathogenic strains. Here we describe the deployment of new sequencing technology to extensively sample eight genomes from the Yersinia genus of the family Enterobacteriaceae. The first published sequencing studies on the Yersinia genus have focused exclusively on invasive human disease-causing species that included five Yersinia pestis genome sequences (one of which, strain 91001, is from the avirulent 'microtus' biovar) [9-12], two Yersinia pseudotuberculosis $[13,14]$ and one Yersinia enterocolitica biotype 1B [15]. Primarily a zoonotic pathogen, $Y$. pestis, the causative agent of bubonic
C Biomed Central

(C) 2010 Chen et al.; licensee BioMed Central Ltd. This is an open access article distributed under the terms of the Creative Commons Attribution License (http://creativecommons.org/licenses/by/2.0), which permits unrestricted use, distribution, and reproduction in any medium, provided the original work is properly cited. 
plague and a category A select agent, is a recently emerged lineage that has since undergone global expansion [2]. Following introduction into a human through flea bite [16], $Y$. pestis is engulfed by macrophages and taken to the regional lymph nodes. $Y$. pestis then escapes the macrophages and multiplies to cause a highly lethal bacteremia if untreated with antibiotics. $Y$. pseudotuberculosis and $Y$. enterocolitica (primarily biotype 1B) are enteropathogens that cause gastroenteritis following ingestion and translocation of the Peyer's patches. Like $Y$. pestis, the enteropathogenic Yersiniae can escape macrophages and multiply outside host cells, but unlike their more virulent cogener, they only usually cause self-limiting inflammatory diseases.

The generally accepted pathway for the evolution of these more severe disease-causing Yersiniae is memorably encapsulated by the recipe, 'add DNA, stir, reduce' [17]. In each species DNA has been 'added' by horizontal gene transfer in the form of plasmids and genomic islands. All three human pathogens carry a 70-kb pYV virulence plasmid (also known as $\mathrm{pCD}$ ), which carries the Ysc type III secretion system and Yops effectors [18-20], that is not detected in non-pathogenic species. $Y$. pestis also has two additional plasmids, pMT (also known as pFra), containing the F1 capsule-like antigen and murine toxin, and pPla (also known as pPCP1), which carries plasminogen-activating factor, Pla. $Y$. pestis, Y. pseudotuberculosis, and biotype 1B Y. enterocolitica also contain a chromosomally located, mobile, highpathogenicity island (HPI) [21]. The HPI includes a cluster of genes for biosynthesis of yersiniabactin, an iron-binding siderophore necessary for systemic infection [22]. 'Stir' refers to intra-genomic change, notably the recent expansion of insertion sequences (IS) within $Y$. pestis (3.7\% of the $Y$. pestis CO92 genome [9]) and a high level of genome structural variation [23]. 'Reduce' describes the loss of functions via deletions and pseudogene accumulation in $Y$. pestis $[9,13]$ due to shifts in selection pressure caused by the transition from $Y$. pseudotuberculosis-like enteropathogenicity to a flea-borne transmission cycle. This description of $Y$. pestis evolution is, of course, oversimplified. $Y$. pestis strains show considerable diversity at the phenotypic level and there is evidence of acquisition of plasmids and other horizontally transferred genes [[12,24,25] DNA microarray, $[26,27]]$.

While most attention is focused on the three wellknown human pathogens, several other, less familiar Yersinia species have been split off from $Y$. enterocolitica over the past 40 years based on biochemistry, serology and 16S RNA sequence [28,29]. Y. ruckeri is an agriculturally important fish pathogen that is a cause of 'red mouth' disease in salmonid fish. The species has sufficient phylogenetic divergence from the rest of the
Yersinia genus to stir controversy about its taxonomic assignment [30]. Y. fredricksenii, Y. kristensenii, Y. intermedia, $Y$. mollaretii, $Y$. bercovieri, and $Y$. rohdei have been isolated from human feces, fresh water, animal feces and intestines and foods [28]. There have been reports associating some of the species with human diarrheal infections [31] and lethality for mice [32]. $Y$. aldovae is most often isolated from fresh water but has also been cultured from fish and the alimentary tracts of wild rodents [33]. There is no report of isolation of $Y$. aldovae from human feces or urine [28].

Using microbead-based, massively parallel sequencing by synthesis [34] we rapidly and economically obtained high redundancy genome sequence of the type strains of each of these eight lesser known Yersinia species. From these genome sequences, we were able to determine the core gene set that defines the Yersinia genus and to look for clues to distinguish the genomes of human pathogens from less virulent strains.

\section{Results}

\section{High-redundancy draft genome sequences of eight Yersinia species}

Whole genome shotgun coverage of eight previously unsequenced Yersinia species (Table 1) was obtained by single-end bead-based pyrosequencing [34] using the 454 Life Sciences GS-20 instrument. Each of the eight genomes was sequenced to a high level of redundancy (between 25 and 44 sequencing reads per base) and assembled de novo into large contigs (Table 2; Additional file 1). Excluding contigs that covered repeat regions and therefore had significantly increased copy number, the quality of the sequence of the draft assemblies was high, with less than $0.1 \%$ of the sequence of each genome having a consensus quality score [35] less than 40. Moreover, a more recent assessment of quality of GS-20 data suggests that the scores generated by the 454 Life Sciences software are an underestimation of the true sequence quality [36]. The most common sequencing error encountered when assembling pyrosequencing data is the rare calling of incorrect numbers of homopolymers caused by variation in the intensity of fluorescence emitted upon extension with the labeled nucleoside [34].

Previous studies and our experience suggest that at this level of sequence coverage the assembly gaps fall in repeat regions that cannot be spanned by single-end sequence reads (average length 109 nucleotides in this study) [34]. Fewer RNA genes are observed compared to published Yersinia genomes finished using traditional Sanger sequencing technology (Additional file 1), reflecting the greater difficulty of uniquely assembling repetitive sequences with single-end reads. We assessed the quality of our assemblies using metrics implemented in 
Table 1 Strains sequenced in this study

\begin{tabular}{|c|c|c|c|c|c|c|c|}
\hline Species & $\begin{array}{l}\text { ATCC } \\
\text { number }\end{array}$ & $\begin{array}{l}\text { Other } \\
\text { designations }\end{array}$ & $\begin{array}{c}\text { Year } \\
\text { isolated }\end{array}$ & $\begin{array}{l}\text { Location } \\
\text { isolated }\end{array}$ & Description & $\begin{array}{c}\text { Optimum } \\
\text { growth } \\
\text { temperature }\end{array}$ & Reference \\
\hline Y. aldovae & $35236 \mathrm{~T}$ & CNY 6065 & NR & Czechoslovakia & Drinking water & $26^{\circ} \mathrm{C}$ & {$[100]$} \\
\hline Y. bercovieri & 43970T & CDC 2475-87 & $N R$ & France & Human stool & $26^{\circ} \mathrm{C}$ & [101] \\
\hline Y. frederiksenii & $33641 \mathrm{~T}$ & $\begin{array}{l}\text { CDC 1461-81, CIP } \\
80-29\end{array}$ & NR & Denmark & Sewage & $26^{\circ} \mathrm{C}$ & [102] \\
\hline Y. intermedia & 29909T & CIP 80-28 & NR & $N R$ & Human urine & $37^{\circ} \mathrm{C}$ & [103] \\
\hline Y. kristensenii & $33638 \mathrm{~T}$ & CIP 80-30 & NR & NR & Human urine & $26^{\circ} \mathrm{C}$ & [104] \\
\hline Y. mollaretii & 43969T & CDC 2465-87 & NR & USA & Soil & $26^{\circ} \mathrm{C}$ & [101] \\
\hline Y. rohdei & 43380T & $\begin{array}{l}\mathrm{H} 271-36 / 78, \mathrm{CDC} \\
3022-85\end{array}$ & 1978 & Germany & Dog feces & $26^{\circ} \mathrm{C}$ & [105] \\
\hline Y. ruckeri & $29473 T$ & 2396-61 & 1961 & Idaho, USA & $\begin{array}{l}\text { Rainbow trout (Oncorhynchus } \\
\text { mykiss) with red mouth disease }\end{array}$ & $26^{\circ} \mathrm{C}$ & [67] \\
\hline
\end{tabular}

NR, not reported in reference publication.

Table 2 Genomes summary

\begin{tabular}{|c|c|c|c|c|c|c|c|c|}
\hline Species & Type strain & $\begin{array}{l}\text { NCBI } \\
\text { project } \\
\text { ID }\end{array}$ & $\begin{array}{l}\text { GenBank } \\
\text { accession } \\
\text { number }\end{array}$ & $\begin{array}{l}\text { Total } \\
\text { reads }\end{array}$ & $\begin{array}{c}\text { Number of } \\
\text { contigs }>500 \\
\text { nt }\end{array}$ & $\begin{array}{l}\text { Total length of } \\
\text { large contigs }\end{array}$ & $\begin{array}{c}\% \text { large } \\
\text { contigs } \\
<Q 40\end{array}$ & $\begin{array}{l}\text { Number of contigs aligned } \\
\text { to chromosomal scaffold }\end{array}$ \\
\hline Y. rohdei & ATCC_43380 & 29767 & $\begin{array}{l}\text { [Genbank: } \\
\text { ACCD00000000] }\end{array}$ & 991,106 & 83 & $4,303,720$ & 0.11 & 60 \\
\hline Y. ruckeri & ATCC_29473 & 29769 & $\begin{array}{l}\text { [Genbank: } \\
\text { ACCC00000000] }\end{array}$ & $1,347,304$ & 103 & $3,716,658$ & 0.004 & 68 \\
\hline Y. aldovae & ATCC_35236 & 29741 & $\begin{array}{l}\text { [Genbank: } \\
\text { ACCB00000000] }\end{array}$ & $1,125,002$ & 104 & $4,277,123$ & 0.006 & 60 \\
\hline Y. kristensenii & ATCC_33638 & 29761 & $\begin{array}{l}\text { [Genbank: } \\
\text { ACCA00000000] }\end{array}$ & $1,374,452$ & 86 & $4,637,246$ & 0.003 & 63 \\
\hline Y. intermedia & ATCC_29909 & 29755 & $\begin{array}{l}\text { [Genbank: } \\
\text { AALF00000000] }\end{array}$ & $1,768,909$ & 74 & $4,684,150$ & 0.003 & 68 \\
\hline Y. frederiksenii & ATCC_33641 & 29743 & $\begin{array}{l}\text { [Genbank: } \\
\text { AALE00000000] }\end{array}$ & $1,504,985$ & 90 & $4,864,031$ & 0.005 & 56 \\
\hline Y. mollaretii & ATCC_43969 & 16105 & $\begin{array}{l}\text { [Genbank: } \\
\text { AALD00000000] }\end{array}$ & $1,825,876$ & 110 & $4,535,932$ & 0.003 & 80 \\
\hline Y. bercovieri & ATCC_43970 & 16104 & $\begin{array}{l}\text { [Genbank: } \\
\text { AALC00000000] }\end{array}$ & $1,263,275$ & 144 & $4,316,521$ & 0.006 & 91 \\
\hline
\end{tabular}

the amosvalidate package [37]. Specifically, we focused on three measures frequently correlated with assembly errors: density of polymorphisms within assembled reads, depth of coverage, and breakpoints in the alignment of unassembled reads to the final assembly. Regions in each genome where at least one measure suggested a possible mis-assembly were validated by manual inspection (Additional file 2). Many of the suspect regions corresponded to collapsed repeats, where the location of individual members of the repeat family within the genome could not be accurately determined. Based on the results of the amosvalidate analysis and the optical map alignment we found no evidence of mis-assemblies leading to chimeric contigs in the eight genomes we sequenced. Genomic regions flagged by the amosvalidate package are made available in GFF format (compatible with most genome browsers) in Additional file 3.
Genome sizes were estimated initially as the sum of the sizes of the contigs from the shotgun assembly, with corrections for contigs representing collapsed repeats (Table 2). We also derived an independent estimate for the genome size from the whole-genome optical restriction mapping of the species [38] (Additional file 4). Alignment of contigs to the optical maps [39] suggested that the optical maps consistently overestimated sizes (2 to $10 \%$ on average). After correction, the map-based estimates and sequence-based estimates agreed well (within 7\%). Two species, $Y$. aldovae (4.22 to $4.33 \mathrm{Mbp}$ ) and $Y$. ruckeri (3.58 to $3.89 \mathrm{Mbp}$ ), have a substantially reduced total genome size compared with the 4.6 to 4.8 $\mathrm{Mbp}$ seen in the genus generally. The agreement between the optical maps and sequence-based estimates of genome sizes tallied with experimental evidence for the lack of large plasmids in the sequenced genomes (Additional file 5). A screen for matches to known 
plasmid genes produced only a few candidate plasmid contigs, totaling less than $10 \mathrm{kbp}$ of sequence in each genome.

The number of IS elements per genome for the eight species (12 to 167 matches) discovered using the IS finder database [40] was much lower than in the $Y$. pestis genome (1,147 matches; copy numbers estimates took into account the possibility of mis-assembly and were accordingly adjusted; see Methods). Furthermore, the non-pathogenic species with the most IS matches, namely Y. bercovieri (167 matches), Y. aldovae (143 matches) and Y. ruckeri (136 matches), have comparatively smaller genomes. We also searched for novel repeat families using a de novo repeat-finder [41] and collected a non-redundant set of 44 repeat sequence families in the Yersinia genus (Table 3; Additional file 6). Interestingly, the well-known ERIC element [42] was recovered by our de novo search and was found to be present in many copies in all the pathogenic species, but was relatively rare in the non-pathogenic ones. On the other hand, a similar and recently discovered element, YPAL [43] (also recovered by the de novo search), was abundant in all the Yersinia genomes except the fish pathogen $Y$. ruckeri. Insertion sequence IS1541C in the IS finder database, which has expanded in $Y$. pestis (to more than 60 copies), had only a handful of strong matches in $Y$. enterocolitica, $Y$. pseudotuberculosis, and $Y$. bercovieri and no discernable matches in the other Yersinia genomes.

\section{New Yersinia genome data reduce the pool of unique} detection targets for $Y$. pestis and $Y$. enterocolitica

The sequences generated in this study provide new background information for validating genus detection and diagnosis assays targeting pathogenic members of the Yersinia genus. The assay design process commonly starts by computationally identifying genomic regions that are unique to the targeted genus ('signatures') - an ideal signature is shared by all targeted pathogens but not found in a background comprising non-pathogenic near neighbors or in other unrelated microbes. While many pathogens are well characterized at the genomic level, the background set is only sparsely represented in genomic databases, thereby limiting the ability to computationally screen out non-specific candidate assays (false positives). As a result, many assays may fail experimental field tests, thereby increasing the costs of assay development efforts. To evaluate whether the new genomic sequences generated in our study can reduce the incidence of false positives in assay development, we computed signatures for the $Y$. pestis and $Y$. enterocolitica genera using the Insignia pipeline [44], the system previously used to successfully develop assays for the detection of $V$. cholerae [44]. We identified 171 and 100 regions within the genomes of $Y$. pestis and $Y$. enterocolitica, respectively, that represent good candidates for the design of detection assays. In Y. pestis these regions tended to cluster around the origin of replication, whereas in $Y$. enterocolitica there was a more even distribution. The average $\mathrm{G}+\mathrm{C}$ content of the regions for the unique sequences in both species was close to the Yersinia average (47\%) and there was not a strong association with putative genome islands (Additional files 7 , $8,9,10,11,12$, [45]). For both species, most regions overlapped predicted genes (161 of 171 (94\%) and 96 of 100 (96\%) in Y. pestis and Y. pseudotuberculosis, respectively). Interestingly, $171 \mathrm{Y}$. pestis gene regions were spread over only 70 different genes, whereas the $96 Y$. enterocolitica regions were found overlapping only 90 genes. There was no obvious trend in the nature of the genes harboring these putative signals except that many could be arguably classed as 'non-core' functions,

Table 3 Distribution of common repeat sequences

\begin{tabular}{|c|c|c|c|c|c|}
\hline & $\begin{array}{r}\text { ERIC } \\
(127 \mathrm{bp}) \\
\end{array}$ & $\begin{array}{r}\text { YPAL } \\
\text { (167 bp) } \\
\end{array}$ & $\begin{array}{r}\text { Kristensenii } 39 \\
(142 \text { bp) } \\
\end{array}$ & $\begin{array}{r}\text { IS1541C } \\
\text { (708 bp) } \\
\end{array}$ & $\begin{array}{r}\text { Aldovae3 } \\
(154 \mathrm{bp}) \\
\end{array}$ \\
\hline E. coli & 0 & 3 & 5 & 0 & 5 \\
\hline Y. pestis & 54 & 43 & 33 & 61 & 38 \\
\hline Y. pseudotuberculosis & 55 & 52 & 29 & 5 & 36 \\
\hline Y. enterocolitica & 63 & 144 & 100 & 3 & 75 \\
\hline Y. aldovae & 6 & 84 & 46 & 0 & 40 \\
\hline Y. bercovieri & 9 & 45 & 6 & 9 & 13 \\
\hline Y. frederiksenii & 0 & 57 & 6 & 0 & 5 \\
\hline Y. intermedia & 2 & 91 & 48 & 0 & 43 \\
\hline Y. kristensenii & 2 & 99 & 70 & 0 & 59 \\
\hline Y. mollaretii & 6 & 62 & 26 & 0 & 20 \\
\hline Y. rohdei & 0 & 37 & 8 & 0 & 7 \\
\hline Y. ruckeri & 45 & 2 & 0 & 0 & 2 \\
\hline
\end{tabular}

Three of the repeat sequences found using de novo searches matched the known repeat elements ERIC, YPAL, and IS1541C and are identified as such. Kristensenii39 and Aldovae3 are elements found from de novo searches in the $Y$. kristensenii and $Y$. aldovae genomes, respectively. 
encoding phage endonucleases, invasins, hemolysins and hypothetical proteins.

Ten $Y$. pestis-specific and $31 Y$. enterocolitica-specific putative signatures have significant matches in the new genome sequence data (Additional files 7, 8, 9, 10), indicating assays designed within these regions would result in false positive results. This result underscores the need for a further sampling of genomes of the Yersinia genus in order to assist the design of diagnostic assays.

\section{Yersinia whole-genome comparisons}

We performed a multiple alignment of the 11 Yersinia species using the MAUVE algorithm [46] (from here on $Y$. pestis CO92 and Y. pseudotuberculosis IP32953 were used as the representative genomes of their species) and obtained 98 locally collinear blocks (LCBs; Additional files 13, 14, [47]). The mean length of the LCBs was $23,891 \mathrm{bp}$. The shortest block was $1,570 \mathrm{bp}$, and the longest was 201,130 bp. This multiple alignment of the 'core' region on average covered 52\% of each Yersinia genome. The nucleotide diversity $(\Pi)$ for the concatenated aligned region was 0.27 , or an approximate genuswide nucleotide sequence homology of $73 \%$. As expected for a set of bacteria with this level of diversity, the alignment of the genomes shows evidence of multiple large genome rearrangements [23] (Additional file 13).

Using an automated pipeline for annotation and clustering of protein orthologs based on the Markov chain clustering tool MCL [48], we estimated the size of the Yersinia protein core set to be 2,497 and the pan-genome [49] to be 27,470 (Additional files 15, 16, $17,18)$. The core number falls asymptotically as genomes are introduced and hence this estimate is somewhat lower than the recent analysis of only the $Y$. enterocolitica, $Y$. pseudotuberculosis and $Y$. pestis genomes (2,747 core proteins) [15]. We found 681 genes to be in exactly one copy in each Yersinia genome and to be nearly identical in length. We used ClustalW [50] to align the members of this highly conserved set, and concatenated individual gene product alignments to make a dataset of 170,940 amino acids for each of the species. Uninformative characters were removed from the dataset and a phylogeny of the genus was computed using Phylip [51] (Figure 1). The topology of this tree was identical whether distance or parsimony methods were used (Additional files 19, 20) and was also identical to a tree based on the nucleotide sequence of the approximately $1.5 \mathrm{Mb}$ of the core genome in LCBs (see above). The genus broke down into three major clades: the outlying fish pathogen, $Y$. ruckeri; $Y$. pestis $/ Y$. pseudotuberculosis; and the remainder of the 'enterocolitica'-like species. Y. kristensenii ATCC33638T was the nearest neighbor of $Y$. enterocolitica 8081. The outlying position of Y. ruckeri was confirmed further when we analyzed the contribution of the genome to reducing the size of the Yersinia core protein families set. If $Y$. ruckeri was excluded, the Yersinia core would be 2,232 protein families of $\mathrm{N}=2$ rather than 2,072 (Table 4). In contrast, omission of any one of the 10 other species only reduced the set by a maximum of 22 families.

Clustering the significant Cluster of Orthologous Groups (COG) hits [52] for each genome hierarchically (Figure 2) yielded a similar pattern for the three basic clades. The overall composition of the COG matches in each genome, as measured by the proportion of the numbers in each COG supercategory, was similar throughout the genus, with the notable exceptions of the high percentage of group L COGs in Y. pestis due to the expansion of IS recombinases and the relatively low number of group $\mathrm{G}$ (sugar metabolism) COGs in Y. ruckeri (Figure 2).

\section{Shared protein clusters in pathogenic Yersinia: yersiniabactin biosynthesis is the key chromosomal function specific to high virulence in humans}

The Yersinia proteomes were investigated for common clusters in the three high virulence species missing from the low human virulence genomes (Figure 3). Because of the close evolutionary relationship of the 'enterocolictica' clade strains, the number of unique protein clusters in $Y$. enterocolitica was reduced to a greater degree than the more phylogentically isolated $Y$. pestis and $Y$. pseudotuberculosis. Many of the same genome islands identified as recent horizontal acquisition by $Y$. pestis and/or $Y$. pseudotuberculosis $[9,13,15]$ were not present in any of the newly sequenced genomes. However, some genes, interesting from the perspective of the host specificity of the $Y$. pestis $/ Y$. pseutoberculosis ancestor, were detected in other Yersinia species for the first time. These included orthologs of YPO3720/YPO3721, a hemolysin and activator protein in $Y$. intermedia, $Y$. bercovieri and Y. fredricksenii; YPO0599, a heme utilization protein also found in Y. intermedia; and YPO0399, an enhancin metalloprotease that had an ortholog in $Y$. kristensenii (ykris0001_41250). Enhancin was originally identified as a factor promoting baculovirus infection of gypsy moth midgut by degradation of mucin [53]. Other loci in $Y$. pestis/Y. pseudotuberculosis linked with insect infection, the TccC and TcABC toxin clusters [54], were also found in $Y$. mollaretti. In $Y$. mollaretti the Tca and Tcc proteins show about $90 \%$ sequence identity to $Y$. pestis/ $Y$. pseudotuberculsis and share identical flanking chromosomal locations. Further work will need to be undertaken to resolve whether the insertion of the toxin genes in $Y$. mollaretti is an independent horizontal transfer event or occurred prior to divergence of the species. 

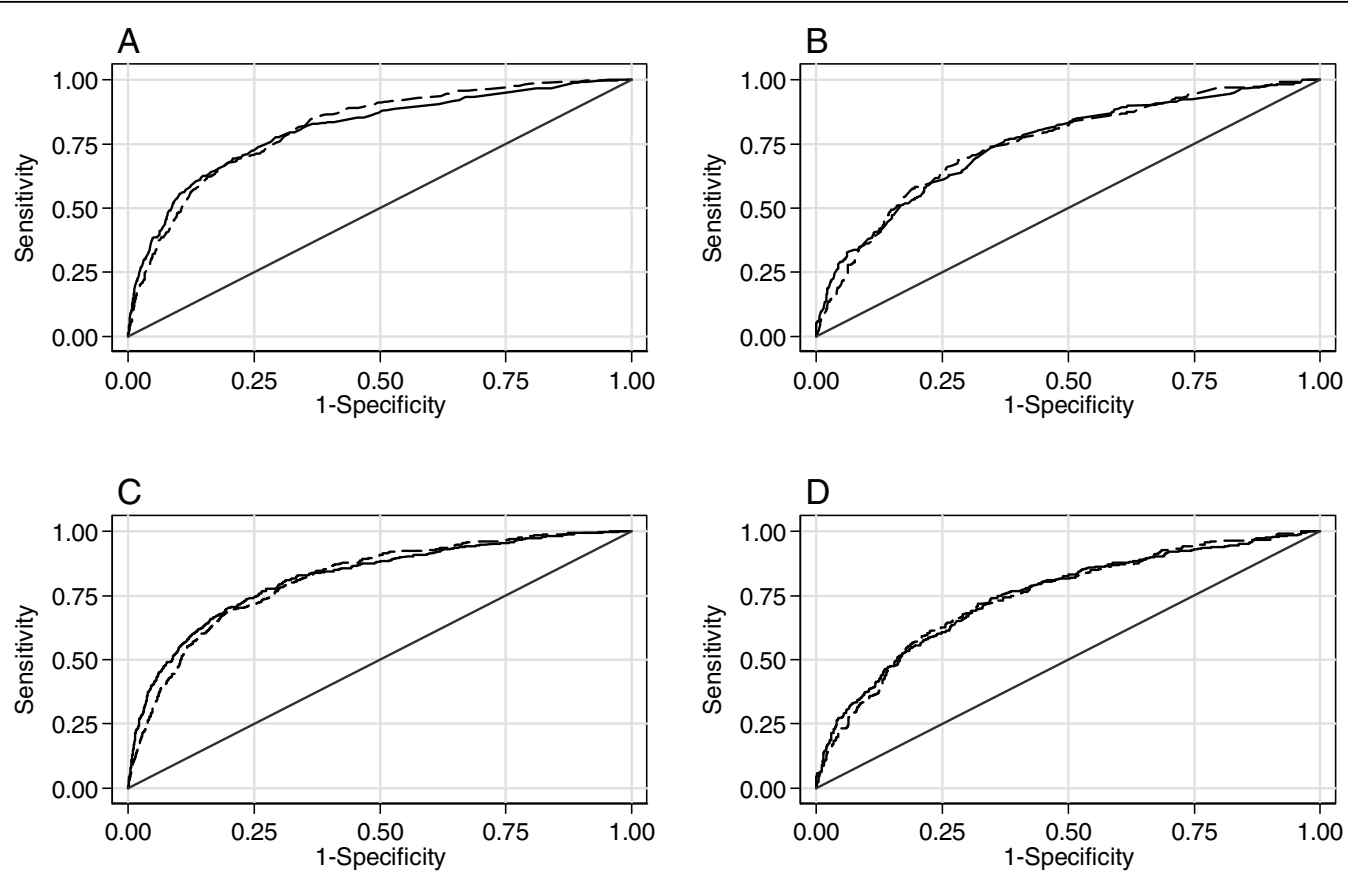

Figure 1 Yersinia whole-genome phylogeny. The phylogeny of the Yersinia genus was constructed from a dataset of 681 concatenated, conserved protein sequences using the Neighbor-Joining (NJ) algorithm implemented by PHYLIP [51]. The tree was rooted using E. coli. The scale measures number of substitutions per residue. Tree topologies computed using maximum likelihood and parsimony estimates are identical with each other and the NJ tree (Additional file 20). The only branches not supported in more than $99 \%$ of the 1,000 bootstrap replicates using both methods are marked with asterisks. Both these branches were supported by $>57 \%$ of replicates.

Table 4 Yersinia core size reduction by exclusion of one species

\begin{tabular}{lc}
\hline Species excluded & Core protein families \\
\hline None & 2,072 \\
Y. enterocolitica & 2,074 \\
Y. aldovae & 2,085 \\
Y. bercovieri & 2,079 \\
Y. frederiksenii & 2,077 \\
Y. intermedia & 2,080 \\
Y. kristensenii & 2,076 \\
Y. mollaretii & 2,078 \\
Y. rohdei & 2,091 \\
Y. ruckeri & 2,232 \\
Y. pseudotuberculosis & 2,076 \\
Y. pestis & 2,094 \\
\hline
\end{tabular}

The core protein families with number of members 2 or greater were recalculated in each case (see Materials and methods) with the protein set from one genome missing.

After comparison of the new low virulence genomes, the number of protein clusters shared by $Y$. enterocolitica and the other two pathogens was reduced to 12 and 13 for $Y$. pseudotuberculosis and $Y$. pestis, respectively (Figure 3). The remaining shared proteins were either identified as phage-related or of unknown role, providing few clues to possible functions that might define distinct pathogenic niches. Performing a similar analysis strategy between others genome of the 'enterocolitica' clade and $Y$. pestis or $Y$. pseudotuberculosis gave a similar result in terms of numbers and types of shared protein clusters.

Only sixteen clusters of chromosomal proteins were found to be common to all three high-virulence species but absent from all eight non-pathogens (Figure 3). Eleven of these are components of the yersiniabactin biosynthesis operon (Additional file 21), further highlighting the critical importance of this iron binding siderophore for invasive disease. The other proteins are generally small proteins that are likely included because they fall in unassembled regions of the eight draft genomes. One other small island of three proteins constituting a multi-drug efflux pump (YE0443 to YE0445) was common to the high-virulence species but missing from the eight draft low-virulence species.

\section{Variable regions of $Y$. enterocolitica clade genomes}

The basic metabolic similarities of $Y$. enterocolitica and the seven species on the main branch of the Yersinia genus phylogenetic tree are further illustrated in Figure 4 , where the best protein matches against each $Y$. enterocolitica 8081 gene product [15] are plotted against a circular genome map. Very few genes exclusive to $Y$. enterocolitica 8081 were found outside of prophage regions, which is a typical result when groups of closely 


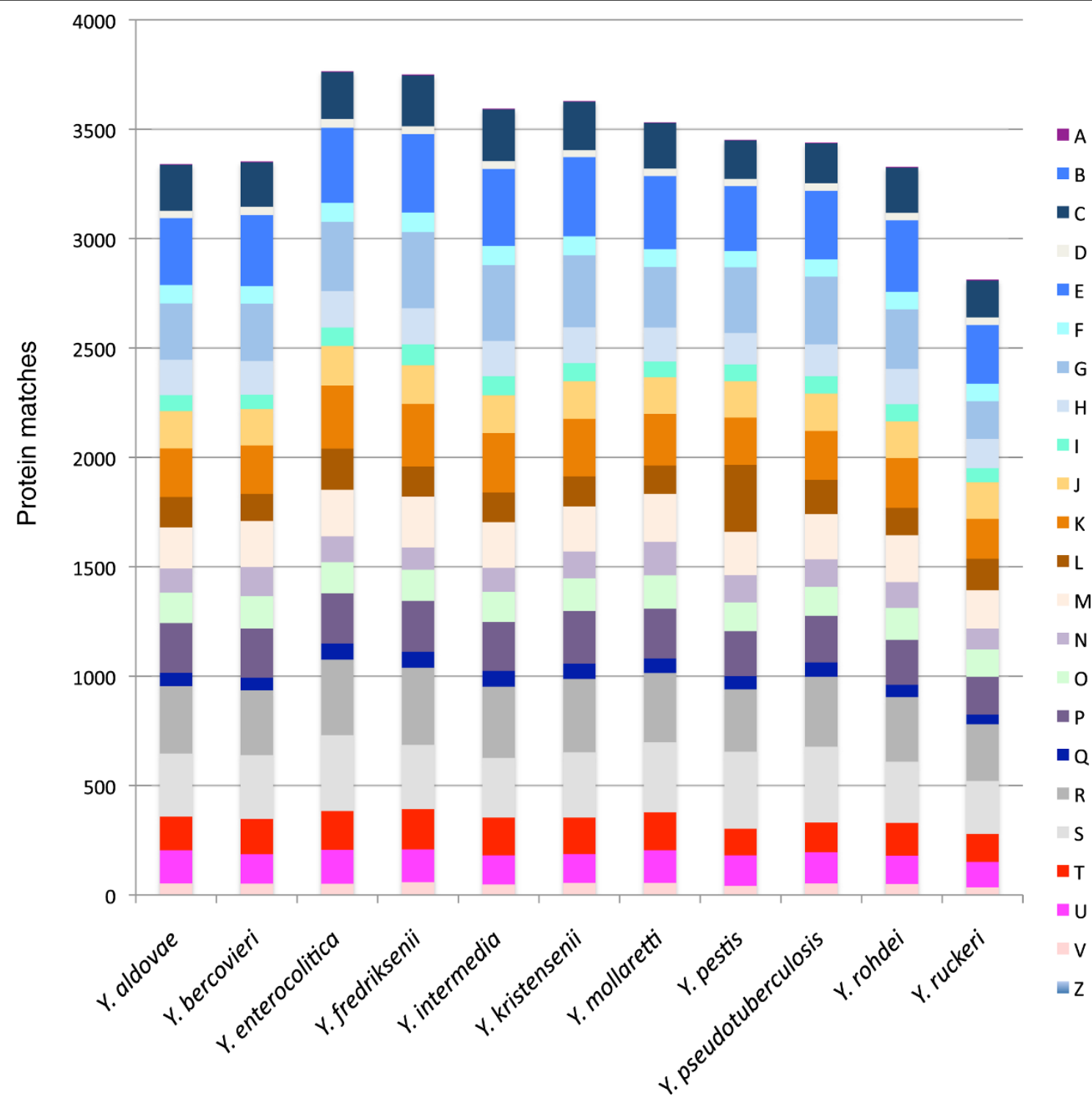

Figure 2 Comparison of major COG groups in Yersinia genomes. Bars represent the number of proteins assigned to COG superfamilies [52] for each genome, based on matches to the Conserved Domain Database [95] database with an E-value threshold $<10^{-10}$. The COG groups are: $U$, intracellular trafficking; $G$, carbohydrate transport and metabolism; R, general function prediction; I, lipid transport and metabolism; D, cell cycle control; $\mathrm{H}$, coenzyme transport and metabolism; B, chromatin structure; $\mathrm{P}$, inorganic ion transport and metabolism; W, extracellular structures; O, post-translational modification; J, translation; A, RNA processing and editing; $L$, replication, recombination and repair; $C$, energy production; $M$, cell wall/membrane biogenesis; $Q$, secondary metabolite biosynthesis; $Z$, cytoskeleton; $V$, defense mechanisms; $E$, amino acid transport and metabolism; $\mathrm{K}$, transcription; N, cell motility; T, signal transduction; F, nucleotide transport; $\mathrm{S}$, function unknown.

related bacterial genomes are compared [55]. One of the largest islands found in $Y$. enterocolitica 8081 was the 66-kb Y. pseudotuberculosis adhesion pathogenicity island $\left(\right.$ YAPI $\left._{\text {ye }}\right)[15,56,57]$, a unique feature of biotype $1 \mathrm{~B}$ strains. YAPI $\mathrm{ye}_{\mathrm{ye}}$, containing a type IV pilus gene cluster and other putative virulence determinants, such as arsenic resistance, is similar to a $99-\mathrm{kb}$ YAPI $_{\mathrm{pst}}$ that is found in several other serotypes of $Y$. pseudotuberculosis $[14,57]$ but is missing in $Y$. pestis and the serotype I $Y$. pseudotuberculosis strain IP32953 [14]. A model has been proposed for the acquisition of YAPI in a common ancestor of $Y$. pseudotuberculosis and $Y$. enterocolitica and subsequent degradation to various degrees within the $Y$. pseudotuberculosis clade. However, the complete absence of YAPI from any of the seven species in the $Y$. enterocolitica branch (Figure 4), as well as from most strains of $Y$. enterocolitica [15], argues against an ancient acquisition of YAPI, but instead suggests the recent 
(a)

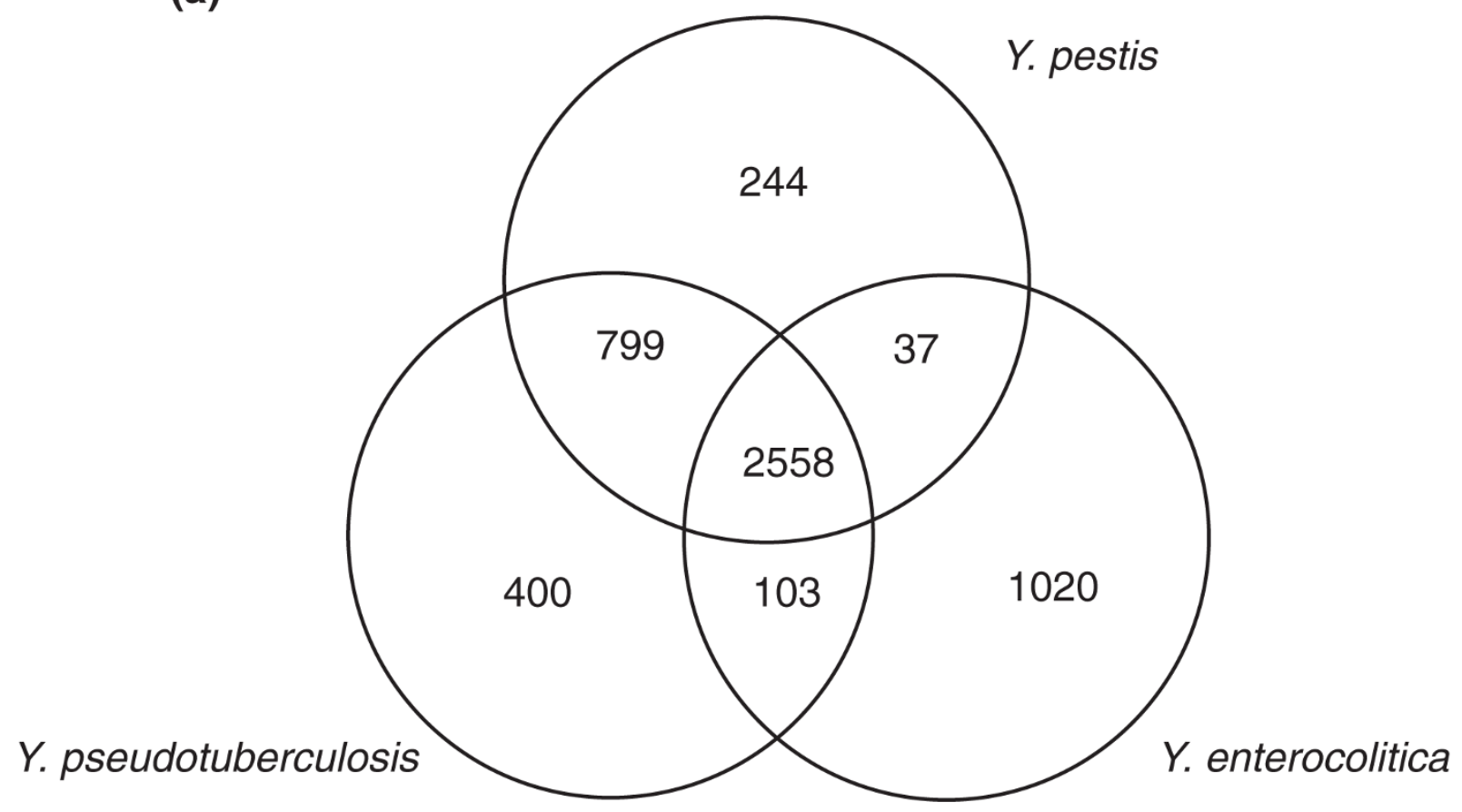

(b)

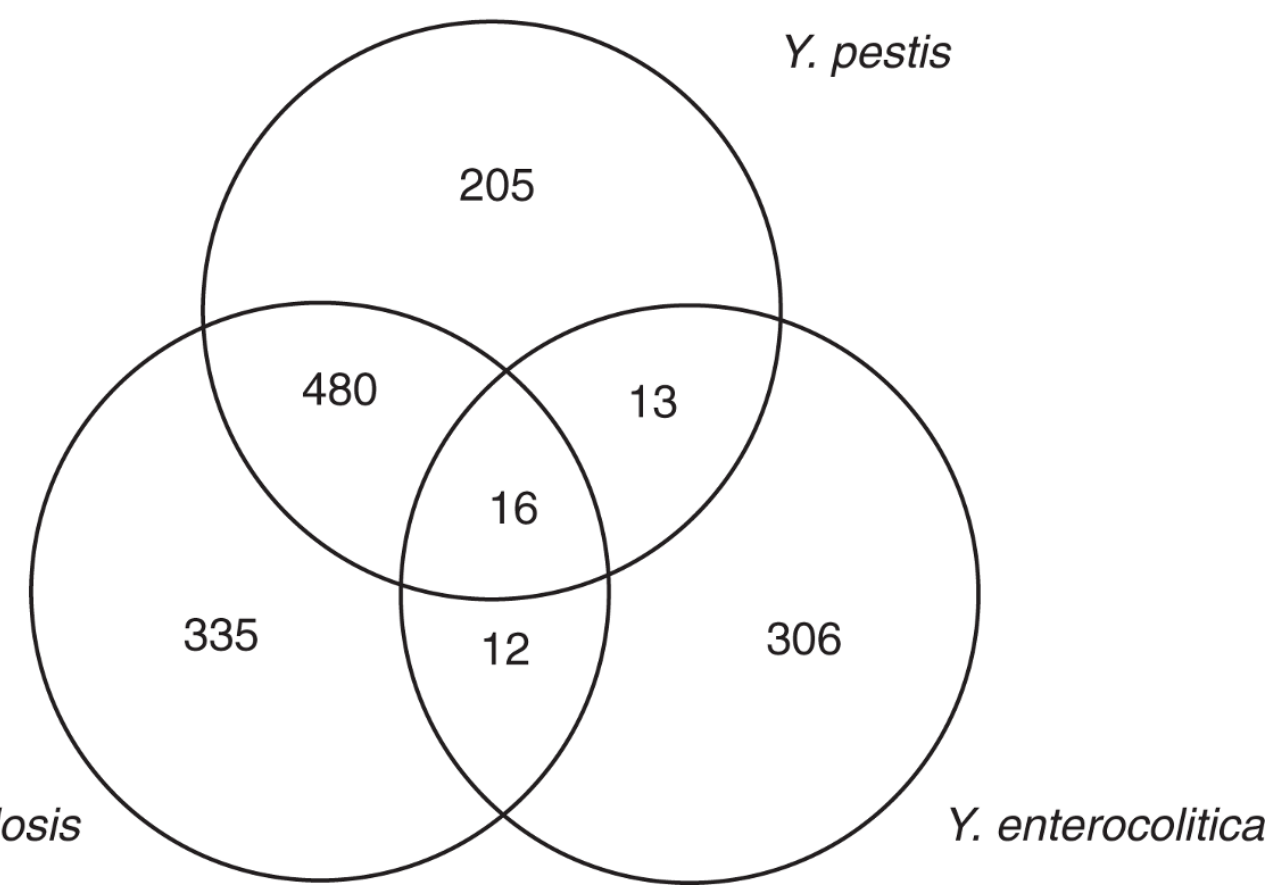

Figure 3 Distribution of protein clusters across Y. enterocolitica 8081, Y. pestis CO92, and Y. pseudotuberculosis IP32953. (a) The Venn diagram shows the number of protein clusters unique or shared between the two other high virulence Yersinia species (see Materials and methods). (b) The number of shared and unique clusters that do not contain a single member of the eight low human virulence genomes sequenced in this study. 


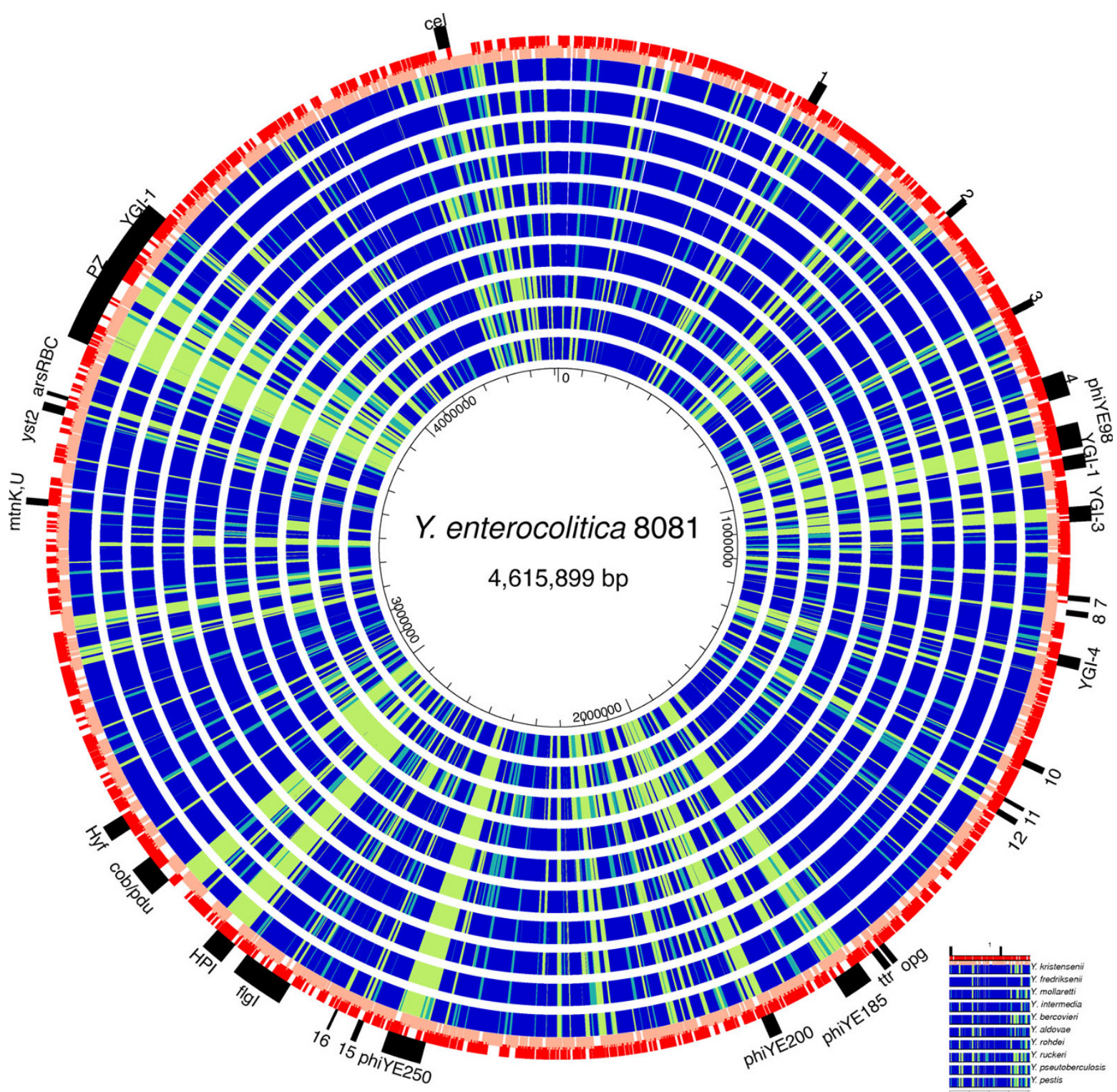

Figure 4 Protein-based comparison of $Y$. enterocolitica $\mathbf{8 0 8 1}$ to the Yersinia genus. The map represents the blast score ratio (BSR) [98,99] to the protein encoded by Y. enterocolitica [15]. Blue indicates a BSR $>0.70$ (strong match); cyan 0.69 to 0.4 (intermediate); green $<0.4$ (weak). Red and pink outer circles are locations of the $Y$. enterocolitica genes on the + and - strands. The genomes are ordered from outside to inside based on the greatest overall similarity to Y. enterocolitica: Y. kristensenii, Y. frederiksenii, Y. mollaretii, Y. intermedia, Y. bercovieri, Y. aldovae, Y. rohdei, Y. ruckeri, $Y$. pseudotuberculosis, and $Y$. pestis. The black bars on the outside refer to genome islands in $Y$. enterocolitica identified by Thomson et al. [15].

independent acquisition of related islands by both $Y$. enterocolitica biogroup 1B and Y. pseudotuberculosis.

Many genes previously thought to be unique to $Y$. enterocolitica in general and biotype 1B in particular turned out to have orthologs in the low human virulence species sequenced in this study. These included several putative biotype 1B-specific genes identified by microarray-based screening [58], including YE0344 HylD hemophore (yinte0001_41550 has 78\% nucleotide identity), YE4052 metalloprotease (yinte0001_36030 has 95\% nucleotide identity), and YE4088, a two-component sensor kinase, which had orthologs in all species. Large portions of the biogroup 1B-specific island containing the Yts1 type II secretion system were found in $Y$. ruckeri, $Y$. mollaretii, and $Y$. aldovae. $Y$. aldovae and $Y$. mollaretii also had islands containing ysa type three secretion systems (TTSS) with 75 to $85 \%$ nucleotide identity to the homolog in $Y$. enterocolitica $1 \mathrm{~B}$. The 
ysagenes are a chromosomal cluster $[9,13,15]$ that in $Y$. enterocolitica, at least, appears to play a role in virulence [59]. The $Y$. enterocolitica ysa genes are found in the plasticity zone (Figure 4) and have very low similarity to the $Y$. pestis and $Y$. pseudotuberculosis ysa genes (which are more similar to the Salmonella SPI-2 island [60,61]) and are found between orthologs of YPO0254 and YPO0274 [9]. Species within the Yersinia genus had either the $Y$. enterocolitica type of ysa TTSS locus or the $Y$. pestis/SPI-2 type (with the exception of $Y$. aldo$v a e$, which has both; Additional file 22). This suggested the exchange of chromosomal TTSS genes within Yersinia.

The modular nature of the islands found in the $Y$. enterocolitica genome was demonstrated further by two examples gleaned from comparison with the evolutionarily closest low human virulence genome, $Y$. kristensenii ATCC 33638T (Figure 1). The YGI-3 island [15] in $Y$. enterocolitica 8081 is a degraded integrated plasmid; at the same chromosomal locus in Y. kristensenii ATCC $33638 \mathrm{~T}$ a prophage was found, suggesting that the YGI3 location may be a recombinational hotspot. Another $Y$. enterocolitica 8081 island, YGI-1, encodes a 'tight adherence' $(t a d)$ locus responsible for non-specific surface binding. Y. kristensenii ATCC 33638T had an identical 13 gene tad locus in the same position, but the nucleotide sequence identity of the region to $Y$. enterocolitica 8081 was uniformly lower than that found for the rest of the genome, suggesting there had been either a gene conversion event replacing the tad locus with a set of new alleles in the recent history of $Y$. kristensenii or $Y$. enterocolitica or the locus was under very high positive selective pressure.

Niche-specific metabolic adaptations in the Yersinia genus Comparison of the $Y$. enterocolitica genome to $Y$. pestis and $Y$. pseudotuberculosis revealed some potentially significant metabolic differences that may account for varying tropisms in gastric infections [62]. Y. enterocolitica 8081 alone contained entire gene clusters for cobalamin (vitamin B12) biosynthesis (cbi), 1,2-propanediol utilization $(p d u)$, and tetrathionate respiration $(t t r)$. In $Y$. enterocolitica and Salmonella typhimurium [63,64], vitamin B12 is produced under anaerobic conditions where it is used as a cofactor in 1,2-propanediol degradation, with tetrathionate serving as an electron acceptor. This study showed the genes for this pathway to be a general feature of species in the 'enterocolitica' branch of the Yersinia genus (with the caveat that some portions are missing in some species; for example, $Y$. rohdei is missing the $p d u$ cluster (Table 5). Additionally, $Y$. intermedia, $Y$. bercovieri, and $Y$. mollaretii contained gene clusters encoding degradation of the membrane lipid constituent ethanolamine. Ethanolamine metabolism under anaerobic conditions also requires the B12 cofactor. Y. intermedia contained the full 17-gene cluster reported in S. typhimurium [65], including structural components of the carboxysome organelle. Another discovery from the $Y$. enterocolitica genome analysis was the presence of two compact hydrogenase gene clusters, Hyd-2 and Hyd-4 [15]. Hydrogen released from fermentation by intestinal microflora is imputed to be an important energy source for enteric gut pathogens [66]. Both gene clusters are conserved across all the other seven enterocolitica-branch species, but are missing from $Y$. pestis and $Y$. pseudotuberculosis. Y. ruckeri contained a single [NiFe]-containing hydrogenase complex.

Y. ruckeri, the most evolutionarily distant member of the genus (Figure 1) with the smallest genome (3.7 Mb), had several features that were distinctive from its cogeners. The $Y$. ruckeri $\mathrm{O}$-antigen operon contained a neuB sialic acid synthase gene, therefore the bacterium was predicted to produce a sialated outer surface structure. Among the common Yersinia genes that are missing

Table 5 Key niche-specific genes in Yersinia

\begin{tabular}{|c|c|c|c|c|c|c|c|c|c|}
\hline & $c b i$ & $p d u$ & $t t r$ & eut & hyd-2 & hyd-4 & ure & $m t n$ & opg \\
\hline Y. enterocolitica & + & + & + & - & + & + & + & + & + \\
\hline Y. aldovae & + & + & - & - & + & + & + & + & + \\
\hline Y. bercovieri & + & + & + & eutABC & + & + & + & + & + \\
\hline Y. frederiksenii & + & + & + & - & + & + & + & + & + \\
\hline Y. intermedia & + & + & + & eUtSPQTDMNEJGHABCLKR & + & + & + & + & + \\
\hline Y. kristensenii & + & + & + & - & + & + & + & + & + \\
\hline Y. mollaretii & + & + & - & eutABC & + & + & + & + & + \\
\hline Y. rohdei & + & - & + & - & + & + & + & + & + \\
\hline Y. ruckeri & - & - & - & - & +/- hyfABCGHINfdhF & +/- (hyaD, hypEDB) & - & - & + \\
\hline Y. pseudotuberculosis & - & - & - & - & - & - & + & + & + \\
\hline Y. pestis & - & - & - & - & - & - & $+/-$ & - & - \\
\hline
\end{tabular}

Abbreviations: cbi, cobalamin (vitamin B12) biosynthesis; pdu, 1,2-propanediol utilization; ttr, tetrathionate respiration; eut, ethanolamine degradation; hyd-2 and hyd-4, hydrogenases 2 and 4, respectively; ure, urease; mtn, methionine salvage pathway; opg, osmoprotectant (synthesis of periplasmic branched glucans). 
only in $Y$. ruckeri were those for xylose utilization and urease activity, consistent with phenotypes that have long been known in clinical microbiology [67] (Table 3). Surprisingly, we discovered that $Y$. ruckeri was also missing the mtnKADCBEU gene cluster that comprises the majority of the methionine salvage pathway [68] found in most other Yersiniae. These genes have also been deleted from $Y$. pestis, but as with $Y$. ruckeri, the $m t n N$ (methylthioadenosine nucleosidase) is maintained. The loss of these genes in $Y$. pestis has been interpreted as a consequence of adaptation to an obligate hostdwelling lifecycle, where the availability of the sulfurcontaining amino acids is not a nutritional limitation [15].

\section{Discussion}

Whole-genome shotgun sequencing by high-throughput bead-based pyrosequencing has proved remarkably useful for the large-scale sequencing of closely related bacteria [49,69-74]. High-quality de novo assemblies can be obtained with relatively few errors and gaps when the sequence read coverage redundancy is 15 -fold or greater. Closing all the gaps in each genome sequence is time-consuming and costly; therefore, in the near future there will be an excess of draft bacterial sequences versus closed genomes in public databases. Our analysis strategy here melds both draft and complete genomes using consistent automated annotation that is scalable to encompass potentially much larger datasets. High quality draft sequencing is likely to shortly supersede comparative genome hybridization using microarrays $[25,58,75,76]$ as the most popular strategy for genomewide bacterial comparisons. Genome sequence datasets can be used to shed light on the novel functions in close relatives that may have been lost in the pathogen of interest, as well as orthologs in genomes that fall below the threshold for hybridization-based detection. The problems of using microarrays for comparisons of more diverse bacterial taxa are illustrated in a study of the Yersinia genus, using many of the strains sequenced in this work, where the estimated number of core genes was found to be only 292 [25].

We cannot claim complete coverage of all the type strains of the Yersinia genus, as three new species have been created [77-79] since our work began. Nonetheless, from this extensive genomic survey we have attempted to categorize the features that define Yersinia. The core of about 2,500 proteins present in all 11 species is not a subset of any other enterobacterial genome. Species of the $Y$. enterocolitica clade (Figure 1) have overall a similar array of protein functions and contain a number of conserved gene clusters (cobalamin, hydrogenases, ureases, and so on) found in other bacteria (Helicobacter, Campylobacter, Salmonella, Escherichia coli) that colonize the mammalian gut. $Y$. pestis has lost many of these genes by deletion or disruption since its split from the enteric pathogen $Y$. pseudotuberculosis and adoption of an insect vector-mediated pathogenicity mode. The smaller $Y$. ruckeri chromosome does not appear to result from recent reductive evolution (as is the case of $Y$. pestis), evidenced by the relatively low number of frameshifts and pseudogenes, and the normal amount of repetitive contigs in the newbler genome assembly. Like $Y$. pestis, $Y$. ruckeri lacks urease, methionine salvage genes, and B12-related metabolism. The prevailing consensus is that the pathway of transmission of red mouth disease in fish is gastrointestinal yet the similarities of $Y$. ruckeri genome reduction to $Y$. pestis hint at an alternative mode of infection for $Y$. ruckeri.

This comparative genomic study reaffirms that the distinguishing features of the high-level mammalian pathogens is the acquisition of a particular set of mobile elements: HPI, the pYV, pMT1 and pPCP plasmids, and the YADI island. However, the eight species sequenced in this study believed to have either low or zero potential for human infection, contain numerous, apparently horizontally transferred genes that would be considered putative virulence determinants if discovered in the genome of a more serious pathogen. Two examples are yaldo0001_40900 (bile salt hydrolase) and yfred0001_36480, an ortholog of the TibA adhesin of enterotoxigenic E. coli. Bile salt hydrolase in pathogenic Brucella abortus has been shown to enhance bile resistance during oral mouse infections [80] and the TibA adhesin forms a biofilm that mediates human cell invasion [81]. The low-virulence species contain a similar (and in some cases greater) number of matches to known drug resistance mechanisms that have been curated in the Antibiotic Resistance Genes Database [82] (Additional file 23, [83]). Adding DNA, stirring and reducing [17] is, therefore, the general recipe for Yersinia genome evolution rather than a formula specific to pathogens. Comparative genomic studies such as these can be used to enhance our ability to rapidly assess the virulence potential of a genome sequence of an emerging pathogen and we plan to continue to build more extensive databases of non-pathogenic Yersinia genomes that will allow us to draw conclusions with more statistical power possible than just 11 representative species.

\section{Conclusions}

Genomes of the 11 Yersinia species studied range in estimated size from 3.7 to $4.8 \mathrm{Mb}$. The nucleotide diversity $(\Pi)$ of the conserved backbone based on large collinear conserved blocks was calculated to be 0.27 . There were no orthologs of genes and predicted proteins in the virulence-associated plasmids pYV, pMT1, and pPla, 
and the HPI of $Y$. pestis in the genomes of the type strains - eight non- or low-pathogenic Yersinia species

Apart from functions encoded on the aforementioned plasmids, HPI and YAPI regions, only nine proteins detected as common to all three Yersinia pathogen species ( $Y$. pestis, $Y$. enterocolitica and $Y$. pseudotuberculosis) were not found on at least one of the other eight species. Therefore, our study is in agreement with the hypothesis that genes acquired by recent horizontal transfer effectively define the members of the Yersinia genus virulent for humans.

The core proteome of the 11 Yersinia species consists of approximately 2,500 proteins. Yersinia genomes had a similar global partition of protein functions, as measured by the distribution of COG families. Genome to genome variation in islands with genes encoding functions such as ureases, hydrogenases and B12 cofactor metabolite reactions may reflect adaptations to colonizing specific host habitats.

$Y$. ruckeri, a salmonid fish pathogen, is the earliest branching member of the genus and has the smallest genome $(3.7 \mathrm{Mb})$. Like $Y$. pestis, Y. ruckeri lacks functional urease, methionine salvage genes, and B12-related metabolism. These losses may reflect adaptation to a lifestyle that does not include colonization of the mammalian gut.

The absence of the YAPI island in any of the seven ' $Y$. enterocolitica clade' genomes likely indicates that YAPI was acquired independently in $Y$. enterocolitica and $Y$. pseudotuberculosis.

We identified 171 and 100 regions within the genomes of $Y$. pestis and $Y$. enterocolitica, respectively, that represented potential candidates for the design of nucleotide sequence-based assays for unique detection of each pathogen.

\section{Materials and methods}

\section{Bacterial strains}

Type strains of the eight Yersinia species sequenced in this study (Table 1) were acquired from the American Type Culture Collection (ATCC) and propagated at $37^{\circ}$ $\mathrm{C}$ or $25^{\circ} \mathrm{C}$ (Y. ruckeri) on Luria media. DNA for genome sequencing was prepared from overnight broth cultures propagated from single colonies streaked on a Luria agar plate using the Promega Wizard Maxiprep System (Promega, Madison, WI, USA).

\section{Genome sequencing and assembly}

Genomes were sequenced using the Genome Sequencer 20 Instrument (454 Life Sequencing Inc., Branford, CT) [34]. Libraries for sequencing were prepared from $5 \mu \mathrm{g}$ of genomic DNA. The sequencing reads for each project were assembled de novo using the newbler program (version 01.51.02; 454 Life Sciences Inc).

\section{Optical mapping}

Optical maps [38] for each genome using the restriction enzymes $A f l \mathrm{II}$ and NheI ( $Y$. aldovae and $Y$. kristensenii only have maps for $A f l \mathrm{II})$ were constructed by Opgen Inc. (Madison, WI). The newbler assemblies for each genome were scaffolded using the optical maps and the SOMA package [39] (Additional file 4). Assemblies that did not align against the optical map were tested for high read coverage, unusual GC content, and good matches to plasmid-associated genes from the ACLAME database [84] (BLAST E-value less than $10^{-20}$ ) to identify sequences that could potentially be part of an extrachromosomal element.

\section{Detection of disrupted genes}

We used two methods for detecting disrupted proteins used. In the first method clustered protein groups were used to adduce evidence for possible gene disruption events. The clusters were parsed for pairs of proteins that met the following criteria: both from the same genome; encoded by genes located on the same strand with less than 200 bp separating their frames; and total length of the combined genes was not greater than $120 \%$ of the longest gene in the cluster. The second method used was the FSFIND algorithm [85] with a standard bacterial gene model to compare the accumulation of predicted frameshifts across different genomes.

\section{Assembly validation}

In order to rule out artifacts due to undocumented features of the newbler assemblies, new assemblies were generated for validation purposes by re-mapping all the shotgun reads to the sequence of the assembled contigs using AMOScmp [86]. The resulting assembly was then subjected to analysis using the amosvalidate package [37]. The output of this program includes a list of genomic regions that contain inconsistencies highlighting possible misassemblies. The resulting regions were manually inspected to reduce the possibility of assembly errors. The regions flagged by the amosvalidate package are provided in GFF (general feature format), compatible with most genome browsers (Additional file 3).

\section{Insertion sequences and de novo repeat finding}

The presence of repeats is known to confound assembly programs and the newbler assembler is known to collapse high-fidelity repeat instances into a single contig. To account for the possibility of such misassemblies, we computed the copy number of contigs based on coverage statistics and used this information to correct our estimates for the abundance of classes of repeats (Additional file 3). To find known insertion sequences, the genomes were scanned for matches using the IS finder web service 
[40] with a BLAST E-value threshold of $10^{-10}$ (matches to known repeat contigs were counted as multiple matches based on the coverage of the contig). In addition, we searched for common repeat sequences in the genome using the RepeatScout program [41] after duplicating known repeat contigs. The repeats found in each genome were collected (64 sequences) and transformed into a non-redundant set of 44 sequences using the CD-HIT program [87] (Additional file 6). The repeats found were then searched against all the genomes using BLAST with an E-value threshold of $10^{-10}$ to record matches. The resultant figures for repeat content are estimations that may be lower than the true number found in the genomes.

\section{Finding unique DNA signatures in $Y$. pestis and $Y$. enterocolitica}

DNA signatures for the $Y$. pestis and the $Y$. enterocolitica genomes were identified using the Insignia pipeline [44]. Signatures of $100 \mathrm{bp}$ or longer were considered good candidates for the design of detection assays. These signatures were then compared with the genomes of the Yersinia strains sequenced during the current study using the MUMmer package [88] with default parameters. Signatures that matched by more than 40 bp were deemed invalidated, as they would likely lead to false-positive results.

\section{Automated annotation}

We used DIYA [89] for automated annotation, which is a pipeline for integrating bacterial analysis tools. Using DIYA, the assemblies generated by newbler were scaffolded based on the optical map, concatenated, and used as a template for the programs GLIMMER [90], tRNASCAN-SE [91], and RNAmmer [92] for prediction of open reading frames and RNA genes, respectively. All predicted proteins encoded by each coding sequence were compared against a database of all proteins predicted from the canonical annotation of $Y$. pestis CO92 [9] as a preliminary screen for potentially novel functions. The GenBank format files created from the eight genomes sequenced in this study were combined with other DIYA-annotated, published whole genomes to form a dataset for analysis. All proteins were searched against the UniRef50 database (July 2008) [93] using BLASTP [94] and against the Conserved Domain Database [95] using RPSBLAST [96] with an E-value threshold of $10^{-10}$ to record matches.

\section{Database accession numbers}

The annotated genome data were submitted to NCBI GenBank and the sequence data submitted to the NCBI
Short Read Archive (SRA). The accession numbers are: Y. rohdei, ATCC_43380: [Genbank:ACCD00000000]/ [SRA:SRA009766.1]; Y. ruckeri ATCC_29473: [Genbank: ACCC00000000]/[SRA:SRA009767.1]; Y. aldovae ATCC_35236: [Genbank:ACCB00000000]/[SRA: SRA009760.1]; Y. kristensenii ATCC_33638: [Genbank: ACCA00000000]/[SRA:SRA009764.1]; Y. intermedia ATCC_29909: [Genbank:AALF00000000]/[SRA: SRA009763.1]; Y. frederiksenii ATCC_33641: [Genbank: AALE00000000]/[SRA:SRA009762.1]; Y. mollaretii ATCC_43969: [Genbank:AALD00000000]/[SRA: SRA009765.1]; Y. bercovieri ATCC_43970: [Genbank: AALC00000000]/[SRA:SRA009761.1].

\section{Whole-genome alignment using MAUVE}

Yersinia genomes were aligned using the standard MAUVE [46] algorithm with default settings. A cutoff for $1,500 \mathrm{bp}$ was set as the minimum LCB length. LCBs for each genome were extracted from the output of the program and concatenated. From the alignment nucleotide diversity was calculated by an in-house script using positions where there was a base in all 11 genomes. Because of the size of the dataset, the calculated value of $\Pi$ is very robust in terms of sequence error. We calculated that 112,696 nucleotides of sequence in the concatenated core would have to be wrong to alter the estimation of $P$ by $\pm 5 \%$ (Additional file 24). PHYLIP [51] programs were used to build a consensus tree of the MAUVE alignment with bootstrapping 1,000 replicates. The underlying model for each replicate was Fitch-Margoliash. The final phylogeny was resolved according to the majority consensus rule.

\section{Clustering protein orthologs}

The complete predicted proteome from all genomes annotated in this study was searched against itself using BLASTP with default parameters. We removed short, spurious, and non-homologous hits by setting a bitscore/alignment length filtering threshold of 0.4 and minimum protein length of 30 . Predicted proteins passing this filter were clustered into families based on these normalized distances using the MCL algorithm [48] with an inflation parameter value of 4 . These parameters were based on an investigation of clustering 12 completed E. coli genomes, which produced very similar results to a previous study [42].

\section{Whole genome phylogenetic reconstruction}

From the results of clustering analysis, 681 proteins were found that had exactly one member in each of the genomes and the length of each protein in the cluster was nearly identical. These protein sequences were 
aligned using ClustalW [50], and individual gene alignments were concatenated into a string of 170,940 amino acids for each genome. Uninformative characters were removed from the dataset using Gblocks [97] and a phylogeny reconstructed with PHYLIP [51] under a neighbor-joining model. To evaluate node support, a majority rule-consensus tree of 1,000 bootstrap replicates was computed.

Additional file 1: Statistics from DIYA and frameshift detection programs on eight genomes sequenced in this study and other enterobacterial genomes from NCBI Statistics from running DIYA [89] and frameshift detection programs on the eight genomes sequenced in this study and various other enterobacterial genomes downloaded from NCBI.

Click here for file

[http://www.biomedcentral.com/content/supplementary/gb-2010-11-1-r1S1.xls ]

Additional file 2: Results of amosvalidate analysis on the eight genomes of this study Results of amosvalidate [37] analysis on the eight genomes of this study.

Click here for file

[http://www.biomedcentral.com/content/supplementary/gb-2010-11-1-r1S2.doc ]

Additional file 3: Additional annotation files These consist of ISfinder [40], RepeatScout [41]and amosvalidate [37] results (GFF format); repeats found by RepeatScout in fasta format, scaffold files (NCBI AGP format); and information about length of contigs, read count, estimated repeat number, count in scaffold and whether or not the contig was placed by SOMA [39].

Click here for file

[http://www.biomedcentral.com/content/supplementary/gb-2010-11-1-r1S3.gz]

Additional file 4: Estimates for genome sizes (in Mbp) based on optical map data Estimates for genome sizes (in Mbp) based on optical map data.

Click here for file

[http://www.biomedcentral.com/content/supplementary/gb-2010-11-1-r1S4.doc ]

Additional file 5: Pulsed field gel analysis of the eight sequenced Yersinia species and failure to detect plasmids An E. coli strain with known plasmids was a positive control.

Click here for file

[http://www.biomedcentral.com/content/supplementary/gb-2010-11-1-r1S5.doc]

Additional file 6: Sequences of the detected repeat families

Sequences of the detected repeat families.

Click here for file

[http://www.biomedcentral.com/content/supplementary/gb-2010-11-1-r1S6.txt ]

Additional file 7: $Y$. pestis CO92 signatures longer than $100 \mathrm{bp}$ computed by the Insignia pipeline $Y$. pestis $\mathrm{CO} 22$ signatures longer than $100 \mathrm{bp}$ computed by the Insignia [44] pipeline.

Click here for file

[http://www.biomedcentral.com/content/supplementary/gb-2010-11-1-r1S7.txt ]

Additional file 8: Sequences of the new genomes that match (that is, invalidate) the $Y$. pestis CO92 signatures listed in Additional file 7 Sequences of the new genomes that match (that is, invalidate) the $Y$. pestis CO92 signatures listed in Additional file 7 .

Click here for file

[http://www.biomedcentral.com/content/supplementary/gb-2010-11-1-r1S8.txt ]
Additional file 9: $Y$. enterocolitica signatures longer than $100 \mathrm{bp}$ computed by the Insignia pipeline $Y$. enterocolitica signatures longer than 100 bp computed by the Insignia pipeline.

Click here for file

[http://www.biomedcentral.com/content/supplementary/gb-2010-11-1-r1S9.txt]

Additional file 10: Sequences of the new genomes that match (that is, invalidate) the $Y$. enterocolitica signatures Sequences of the new genomes that match (that is, invalidate) the $Y$. enterocolitica signatures. Click here for file

[http://www.biomedcentral.com/content/supplementary/gb-2010-11-1-r1S10.txt]

Additional file 11: $Y$. pestis genome with the Insiginia-indentified repeats and genome islands plotted $Y$. pestis genome with the Insiginia-indentified repeats and genome islands identified using IslandViewer [45] plotted. The figure was created using DNAPlotter [106]. Click here for file

[http://www.biomedcentral.com/content/supplementary/gb-2010-11-1-r1S11.png ]

Additional file 12: $Y$. enterocolitica genome with the Insiginiaindentified repeats and genome plotted $Y$. enterocolitica genome with the Insiginia-indentified repeats and genome islands identified using IslandViewer [45] plotted. The figure was created using DNAPlotter [106]. Click here for file

[http://www.biomedcentral.com/content/supplementary/gb-2010-11-1-r1S12.png ]

Additional file 13: Output of the MAUVE [46] alignment of 11 Yersinia species The eight genomes sequenced in this study are represented as pseudocontigs, ordered by a combination of optical mapping and alignment to the closest completed reference genome.

Click here for file

[http://www.biomedcentral.com/content/supplementary/gb-2010-11-1-r1S13.jpeg ]

Additional file 14: Whole genome multiple alignment produced by MAUVE of the 11 Yersinia genomes Whole genome multiple alignment produced by MAUVE of the 11 Yersinia genomes in XMFA format [106]. Click here for file

[http://www.biomedcentral.com/content/supplementary/gb-2010-11-1-r1S14.zip ]

Additional file 15: Output of the cluster analysis of the 11 Yersinia species The top level directory consists of a directory called

Additional_cluster_files and 5010 directories, one for each multi-protein cluster family. (This top level directory has been split into three data files for uploading purposes (Additional files 15, 16, 17).) Within the directory are the following files: PGL1_unique_Yersinia_unclustered.out - list of all protein singletons that $M C L$ did not group into a cluster (see Materials and Methods); PGL1_Yersinia_unique_locus_tags.txt - names of the 11 locus tag prefixes used for each genome; PGL1_unique_Yersinia.gff mapping each Yersinia protein to a cluster in tab delimited GFF; PGL1_unique_Yersinia.sigfile - list of the longest protein in each cluster; PGL1_unique_Yersinia.summary - summary table of features of each of the clusters; PGL1_unique_Yersinia.table - summary table of each protein in the clusters. Within each cluster directory are the following files, where ' $x$ ' is the cluster name: PGL1 unique Yersinia-x.faa - multifasta file of the proteins in the cluster; PGL1_unique_Yersinia-x.summary - summary of the properties of the proteins; PGL1_unique_Yersinia-x.matches - blast matches between the proteins of the cluster; PGL1_unique_Yersinia-x. muscle.fasta - muscle alignment of the proteins; PGL1_unique_Yersinia-X. muscle.fasta.gblo - gblocks output of muscle alignment (that is, autotrimmed alignment); PGL1_unique_Yersinia-x.muscle.fasta.gblo.htm - as above in html format; PGL1_unique_Yersinia-x.muscle.tree - treefile from muscle alignment; PGL1_unique_Yersinia-x.sif - matches between proteins in simple interaction format for display on graphing software. Click here for file

[http://www.biomedcentral.com/content/supplementary/gb-2010-11-1-r1S15.zip ] 
Additional file 16: Output of the cluster analysis of the 11 Yersinia species The top level directory consists of a directory called

Additional_cluster_files and 5010 directories, one for each multi-protein cluster family. (This top level directory has been split into three data files for uploading purposes (Additional files 15, 16, 17.) Within the directory are the following files: PGL1_unique_Yersinia_unclustered.out - list of all protein singletons that $\mathrm{MCL}$ did not group into a cluster (see Materials and Methods); PGL1_Yersinia_unique_locus_tags.txt - names of the 11 locus tag prefixes used for each genome; PGL1_unique_Yersinia.gff mapping each Yersinia protein to a cluster in tab delimited GFF; PGL1_unique_Yersinia.sigfile - list of the longest protein in each cluster; PGL1_unique_Yersinia.summary - summary table of features of each of the clusters; PGL1_unique_Yersinia.table - summary table of each protein in the clusters. Within each cluster directory are the following files, where ' $x$ ' is the cluster name: PGL1_unique_Yersinia-x.faa - multifasta file of the proteins in the cluster; PGL1_unique_Yersinia-X.summary - summary of the properties of the proteins; PGL1_unique_Yersinia-x.matches - blast matches between the proteins of the cluster; PGL1_unique_Yersinia-X. muscle.fasta - muscle alignment of the proteins; PGL1_unique_Yersinia-X. muscle.fasta.gblo - gblocks output of muscle alignment (that is, autotrimmed alignment); PGL1_unique_Yersinia-x.muscle.fasta.gblo.htm - as above in html format; PGL1_unique_Yersinia-x.muscle.tree - treefile from muscle alignment; PGL1_unique_Yersinia-x.sif - matches between proteins in simple interaction format for display on graphing software. Click here for file

[http://www.biomedcentral.com/content/supplementary/gb-2010-11-1-r1S16.zip ]

\section{Additional file 17: Output of the cluster analysis of the 11 Yersinia} species The top level directory consists of a directory called Additional_cluster_files and 5010 directories, one for each multi-protein cluster family. (This top level directory has been split into three data files for uploading purposes (Additional files 15, 16, 17.) Within the directory are the following files: PGL1_unique Yersinia unclustered.out - list of al protein singletons that $\mathrm{MCL}$ did not group into a cluster (see Materials and Methods): PGL1 Yersinia unique locus tags.txt - names of the 11 locus tag prefixes used for each genome; PGL1_unique_Yersinia.gff mapping each Yersinia protein to a cluster in tab delimited GFF; PGL1_unique_Yersinia.sigfile - list of the longest protein in each cluster; PGL1_unique_Yersinia.summary - summary table of features of each of the clusters; PGL1_unique_Yersinia.table - summary table of each protein in the clusters. Within each cluster directory are the following files, where ' $x$ ' is the cluster name: PGL1_unique_Yersinia-x.faa - multifasta file of the proteins in the cluster; PGL1_unique_Yersinia-x.summary - summary of the properties of the proteins; PGL1_unique_Yersinia-x.matches - blast matches between the proteins of the cluster; PGL1_unique_Yersinia- $x$. muscle.fasta - muscle alignment of the proteins; PGL1_unique_Yersinia-X. muscle.fasta.gblo - gblocks output of muscle alignment (that is, autotrimmed alignment); PGL1_unique_Yersinia-x.muscle.fasta.gblo.htm - as above in html format; PGL1_unique_Yersinia-x.muscle.tree - treefile from muscle alignment; PGL1_unique_Yersinia-x.sif - matches between proteins in simple interaction format for display on graphing software. Click here for file

[http://www.biomedcentral.com/content/supplementary/gb-2010-11-1-r1S17.zip ]

Additional file 18: Complete protein sets for the 11 species of Yersinia Complete protein sets for the 11 species of Yersinia.

Click here for file

[http://www.biomedcentral.com/content/supplementary/gb-2010-11-1-r1S18.zip ]

Additional file 19: Inferred evolutionary trees reconstructed using PHYLIP [51] of the 11 Yersinia species proteomes based on

parsimony To evaluate node support, a majority rule-consensus tree of 1,000 bootstrap replicates was computed. E. coli was used as an outgroup species.

Click here for file

[http://www.biomedcentral.com/content/supplementary/gb-2010-11-1-r1S19.pdf]
Additional file 20: Inferred evolutionary trees reconstructed using PHYLIP [51] of the 11 Yersinia species proteomes based on maximum likelihood To evaluate node support, a majority ruleconsensus tree of 1,000 bootstrap replicates was computed. E. coli was used as an outgroup species.

Click here for file

[http://www.biomedcentral.com/content/supplementary/gb-2010-11-1-r1S20.pdf ]

Additional file 21: Twenty proteins conserved in pathogenic strains but missing from the non-pathogen set $A$ curve showing the rate of decline in number of this set as more non-pathogen genomes are added is also included.

Click here for file

[http://www.biomedcentral.com/content/supplementary/gb-2010-11-1-r1S21.doc ]

Additional file 22: Phylogeny of TTSS component $\mathrm{YscN}$ in Yersinia and other enterobacteria species Phylogeny of TTSS component $Y_{S C N}$ in Yersinia and other enterobacteria species.

Click here for file

[ http://www.biomedcentral.com/content/supplementary/gb-2010-11-1-r1S22.doc]

Additional file 23: Putative antibiotic resistance genes in the Yersinia genus determined using the Antibiotic Resistance Genes Database Putative antibiotic resistance genes in the Yersinia genus determined using the Antibiotic Resistance Genes Database [45]. Click here for file

[ http://www.biomedcentral.com/content/supplementary/gb-2010-11-1-r1S23.xls ]

Additional file 24: Calculations for the estimation of $\Pi$ from aligned Yersinia core genomes Calculations for the estimation of $\Pi$ from

aligned Yersinia core genomes.

Click here for file

[http://www.biomedcentral.com/content/supplementary/gb-2010-11-1-r1S24.doc ]

\section{Abbreviations}

ATCC: American Type Culture Collection; COG: Cluster of Orthologous Groups; HPI: high-pathogenicity island; IS: insertion sequence; LCB: locally collinear block; SRA: Short Read Archive; TTSS: type III secretion system; YAPI: Y. pseudotuberculosis adhesion pathogenicity island.

\section{Acknowledgements}

We would like to thank Ayra Akmal, Kim Bishop-Lilly, Mike Cariaso, Brian Osborne, Bill Klimke, Tim Welch, Jennifer Tsai, Cheryl Timms Strauss and members of the 454 Service Center for their help and advice in completing this manuscript. This work was supported by grant TMTI0068_07_NM_T from the Joint Science and Technology Office for Chemical and Biological Defense (JSTO-CBD), Defense Threat Reduction Agency Initiative to TDR. The views expressed in this article are those of the authors and do not necessarily reflect the official policy or position of the US Department of the Navy, US Department of Defense, or the US Government. Some of the authors are employees of the US Government, and this work was prepared as part of their official duties. Title 17 USC $\$ 105$ provides that 'Copyright protection under this title is not available for any work of the United States Government.' Title 17 USC §101 defines a US Government work as a work prepared by a military service member or employee of the US Government as part of that person's official duties.

\section{Author details}

'Biological Defense Research Directorate, Naval Medical Research Center, 503 Robert Grant Avenue, Silver Spring, Maryland 20910, USA. ${ }^{2}$ University of Maryland Institute for Advanced Computer Sciences, Center for Bioinformatics and Computational Biology, University of Maryland, College Park, Maryland 20742, USA. ${ }^{3}$ Emerging Pathogens Institute and Department of Molecular Genetics and Microbiology, University of Florida College of 
Medicine, Gainesville, Florida 32610, USA. ${ }^{4} 454$ Life Sciences Inc., 15 Commercial Street, Branford, Connecticut 06405, USA. ${ }^{5}$ Department of Human Genetics, Emory University School of Medicine, 615 Michael Street, Atlanta, Georgia 30322, USA. ${ }^{6}$ Division of Infectious Diseases, Emory University School of Medicine, 615 Michael Street, Atlanta, Georgia 30322, USA. ${ }^{7}$ Current address: Computational and Mathematical Biology, Genome Institute of Singapore, Singapore-127726.

\section{Authors' contributions}

TDR, MEZ, LD, and SS were involved in study design. AS, and AM were involved in materials. $L D, M P K T, S L$, and NNo were involved in 454 sequencing. SS, MPKT, and CC were involved in additional experiments. PEC, TDR, CC, MEZ, ACS, NN, MP, BT, and DDS were involved in data analysis. TDR, MP, and NN wrote the paper.

Received: 23 May 2009 Revised: 7 October 2009

Accepted: 4 January 2010 Published: 4 January 2010

\section{References}

1. Ecker DJ, Sampath R, Willett P, Wyatt JR, Samant V, Massire C, Hall TA, Hari K, MCNeil JA, Buchen-Osmond C, Budowle B: The Microbial Rosetta Stone Database: a compilation of global and emerging infectious microorganisms and bioterrorist threat agents. BMC Microbiol 2005, 5:19.

2. Achtman M, Zurth K, Morelli G, Torrea G, Guiyoule A, Carniel E: Yersinia pestis, the cause of plague, is a recently emerged clone of Yersinia pseudotuberculosis. Proc Natl Acad Sci USA 1999, 96:14043-14048.

3. van Baarlen P, van Belkum A, Summerbell RC, Crous PW, Thomma BP: Molecular mechanisms of pathogenicity: how do pathogenic microorganisms develop cross-kingdom host jumps?. FEMS Microbiol Rev 2007, 31:239-277.

4. Van Ert MN, Easterday WR, Huynh LY, Okinaka RT, Hugh-Jones ME, Ravel J, Zanecki SR, Pearson T, Simonson TS, U'Ren JM, Kachur SM, LeademDougherty RR, Rhoton SD, Zinser G, Farlow J, Coker PR, Smith KL, Wang B, Kenefic LJ, Fraser-Liggett CM, Wagner DM, Keim P: Global Genetic Population Structure of Bacillus anthracis. PLOS ONE 2007, 2:e461.

5. Zwick ME, McAfee F, Cutler DJ, Read TD, Ravel J, Bowman GR, Galloway DR, Mateczun A: Microarray-based resequencing of multiple Bacillus anthracis isolates. Genome Biol 2005, 6:R10.

6. Ahmed N, Dobrindt U, Hacker J, Hasnain SE: Genomic fluidity and pathogenic bacteria: applications in diagnostics, epidemiology and intervention. Nat Rev Microbiol 2008, 6:387-394.

7. Mardis ER: The impact of next-generation sequencing technology on genetics. Trends Genet 2008, 24:133-141.

8. Shendure J, Ji H: Next-generation DNA sequencing. Nat Biotechnol 2008, 26:1135-1145.

9. Parkhill J, Wren BW, Thomson NR, Titball RW, Holden MT, Prentice MB, Sebaihia M, James KD, Churcher C, Mungall KL, Baker S, Basham D, Bentley SD, Brooks K, Cerdeño-Tárraga AM, Chillingworth T, Cronin A, Davies RM, Davis P, Dougan G, Feltwell T, Hamlin N, Holroyd S, Jagels K, Karlyshev AV, Leather S, Moule S, Oyston PC, Quail M, Rutherford K, et al: Genome sequence of Yersinia pestis, the causative agent of plague. Nature 2001, 413:523-527.

10. Deng W, Burland V, Plunkett G, Boutin A, Mayhew GF, Liss P, Perna NT, Rose DJ, Mau B, Zhou S, Schwartz DC, Fetherston JD, Lindler LE, Brubaker RR, Plano GV, Straley SC, McDonough KA, Nilles ML, Matson JS, Blattner FR, Perry RD: Genome sequence of Yersinia pestis KIM. J Bacteriol 2002, 184:4601-4611

11. Song Y, Tong Z, Wang J, Wang L, Guo Z, Han Y, Zhang J, Pei D, Zhou D, Qin H, Pang X, Han Y, Zhai J, Li M, Cui B, Qi Z, Jin L, Dai R, Chen F, Li S, Ye C, Du Z, Lin W, Wang J, Yu J, Yang H, Wang J, Huang P, Yang R: Complete genome sequence of Yersinia pestis strain 9 an isolate avirulent to humans. DNA Res 2004z, 11:179-197.

12. Chain PS, Hu P, Malfatti SA, Radnedge L, Larimer F, Vergez LM, Worsham P, Chu MC, Andersen GL: Complete genome sequence of Yersinia pestis strains Antiqua and Nepal516: evidence of gene reduction in an emerging pathogen. J Bacteriol 2006, 188:4453-4463.

13. Chain PS, Carniel E, Larimer FW, Lamerdin J, Stoutland PO, Regala WM Georgescu AM, Vergez LM, Land ML, Motin VL, Brubaker RR, Fowler J, Hinnebusch J, Marceau M, Medigue C, Simonet M, Chenal-Francisque V, Souza B, Dacheux D, Elliott JM, Derbise A, Hauser L, Garcia E: Insights into the evolution of Yersinia pestis through whole-genome comparison with
Yersinia pseudotuberculosis. Proc Natl Acad Sci USA 2004, 101:13826-13831.

14. Eppinger M, Rosovitz MJ, Fricke WF, Rasko DA, Kokorina G, Fayolle C, Lindler LE, Carniel E, Ravel J: The complete genome sequence of Yersinia pseudotuberculosis IP31758, the causative agent of Far East scarlet-like fever. PLOS Genet 2007, 3:e142.

15. Thomson NR, Howard S, Wren BW, Holden MT, Crossman L, Challis GL, Churcher C, Mungall K, Brooks K, Chillingworth T, Feltwell T, Abdellah Z, Hauser $\mathrm{H}$, Jagels $\mathrm{K}$, Maddison M, Moule S, Sanders M, Whitehead S, Quail MA, Dougan G, Parkhill J, Prentice MB: The Complete Genome Sequence and Comparative Genome Analysis of the High Pathogenicity Yersinia enterocolitica Strain 8081. PLoS Genet 2006, 2:e206.

16. Rollins SE, Rollins SM, Ryan ET: Yersinia pestis and the plague. Am J Clin Pathol 2003, 119(Suppl):S78-85.

17. Wren BW: The yersiniae-a model genus to study the rapid evolution of bacterial pathogens. Nat Rev Microbiol 2003, 1:55-64.

18. Cornelis GR: The Yersinia Ysc-Yop virulence apparatus. Int J Med Microbiol 2002, 291:455-462

19. Juris SJ, Shao F, Dlxon JE: Yersinia effectors target mammalian signaling pathways. Cell Microbiol 2002, 4:201-211.

20. Viboud GI, Bliska JB: Yersinia outer proteins: role in modulation of host cell signaling responses and pathogenesis. Annu Rev Microbiol 2005, 59:69-89.

21. Schubert S, Rakin A, Heesemann J: The Yersinia high-pathogenicity island (HPI): evolutionary and functional aspects. Int I Med Microbiol 2004, 294:83-94.

22. Carniel $E:$ The Yersinia high-pathogenicity island: an iron-uptake island. Microbes Infect 2001, 3:561-569.

23. Darling $A E$, Miklos I, Ragan MA: Dynamics of genome rearrangement in bacterial populations. PLOS Genet 2008, 4:e1000128.

24. Anisimov AP, Lindler LE, Pier GB: Intraspecific diversity of Yersinia pestis. Clin Microbiol Rev 2004, 17:434-464.

25. Wang X, Han Y, Li Y, Guo Z, Song Y, Tan Y, Du Z, Rakin A, Zhou D, Yang R: Yersinia genome diversity disclosed by Yersinia pestis genome-wide DNA microarray. Can J Microbiol 2007, 53:1211-1221.

26. Welch TJ, Fricke WF, McDermott PF, White DG, Rosso ML, Rasko DA, Mammel MK, Eppinger M, Rosovitz MJ, Wagner D, Rahalison L, Leclerc JE, Hinshaw JM, Lindler LE, Cebula TA, Carniel E, Ravel J: Multiple antimicrobial resistance in plague: an emerging public health risk. PLOS ONE 2007, 2: e309.

27. Derbise A, Chenal-Francisque V, Pouillot F, Fayolle C, Prévost MC, Médigue C, Hinnebusch BJ, Carniel E: A horizontally acquired filamentous phage contributes to the pathogenicity of the plague bacillus. $\mathrm{Mol}$ Microbiol 2007, 63:1145-1157.

28. Sulakvelidze A: Yersiniae other than Y. enterocolitica, Y. pseudotuberculosis, and Y. pestis: the ignored species. Microbes Infect 2000, 2:497-513.

29. Bottone EJ, Bercovier H, Mollaret HH: Genus XLI. Yersinia Van Loghem 1944, 15AL. Bergey's Manual of Systematic Bacteriology 2005, 2:838-846.

30. Kotetishvili M, Kreger A, Wauters G, Morris JG Jr, Sulakvelidze A, Stine OC: Multilocus sequence typing for studying genetic relationships among Yersinia species. J Clin Microbiol 2005, 43:2674-2684.

31. Noble MA, Barteluk RL, Freeman HJ, Subramaniam R, Hudson JB: Clinical significance of virulence-related assay of Yersinia species. J Clin Microbiol 1987, 25:802-807.

32. Robins-Browne RM, Cianciosi S, Bordun AM, Wauters G: Pathogenicity of Yersinia kristensenii for mice. Infect Immun 1991, 59:162-167.

33. Fukushima H, Gomyoda M, Kaneko S: Mice and moles inhabiting mountainous areas of Shimane Peninsula as sources of infection with Yersinia pseudotuberculosis. J Clin Microbiol 1990, 28:2448-2455.

34. Margulies M, Egholm M, Altman WE, Attiya S, Bader JS, Bemben LA, Berka J, Braverman MS, Chen YJ, Chen Z, Dewell SB, Du L, Fierro JM, Gomes XV, Godwin BC, He W, Helgesen S, Ho CH, Ho CH, Irzyk GP, Jando SC, Alenquer ML, Jarvie TP, Jirage KB, Kim JB, Knight JR, Lanza JR, Leamon JH, Lefkowitz SM, Lei $M$, et al: Genome sequencing in microfabricated highdensity picolitre reactors. Nature 2005, 437:376-380.

35. Ewing $B$, Green P: Base-calling of automated sequencer traces using phred. II. Error probabilities. Genome Res 1998, 8:186-194.

36. Brockman W, Alvarez P, Young S, Garber M, Giannoukos G, Lee WL, Russ C, Lander ES, Nusbaum C, Jaffe DB: Quality scores and SNP detection in sequencing-by-synthesis systems. Genome Res 2008, 18:763-770. 
37. Phillippy AM, Schatz MC, Pop M: Genome assembly forensics: finding the elusive mis-assembly. Genome Biol 2008, 9:R55.

38. Samad AH, Cai WW, Hu X, Irvin B, Jing J, Reed J, Meng X, Huang J, Huff E, Porter $B$ : Mapping the genome one molecule at a time-optical mapping. Nature 1995, 378:516-517.

39. Nagarajan N, Read TD, Pop M: Scaffolding and validation of bacterial genome assemblies using optical restriction maps. Bioinformatics 2008, 24:1229-35.

40. Siguier P, Perochon J, Lestrade L, Mahillon J, Chandler M: ISfinder: the reference centre for bacterial insertion sequences. Nucleic Acids Res 2006, 34:D32-36.

41. Price AL, Jones NC, Pevzner PA: De novo identification of repeat families in large genomes. Bioinformatics 2005, 21(Suppl 1):i351-358.

42. Hulton CS, Higgins CF, Sharp PM: ERIC sequences: a novel family of repetitive elements in the genomes of Escherichia coli, Salmonella typhimurium and other enterobacteria. Mol Microbiol 1991, 5:825-834.

43. De Gregorio E, Silvestro G, Venditti R, Carlomagno MS, Di Nocera PP: Structural organization and functional properties of miniature DNA insertion sequences in yersiniae. J Bacteriol 2006, 188:7876-7884.

44. Phillippy AM, Mason JA, Ayanbule K, Sommer DD, Taviani E, Huq A, Colwell RR, Knight IT, Salzberg SL: Comprehensive DNA signature discovery and validation. PLOS Comput Biol 2007, 3:e98.

45. Langille MG, Brinkman FS: IslandViewer: an integrated interface for computational identification and visualization of genomic islands. Bioinformatics 2009, 25:664-665.

46. Darling AC, Mau B, Blattner FR, Perna NT: Mauve: multiple alignment of conserved genomic sequence with rearrangements. Genome Res 2004, 14:1394-1403.

47. MAUVE Aligner User Guide. http://asap.ahabs.wisc.edu/mauve-aligner/ mauve-user-guide/.

48. Enright AJ, Van Dongen S, Ouzounis CA: An efficient algorithm for large-scale detection of protein families. Nucleic Acids Res 2002, 30:1575-1584

49. Tettelin H, Masignani V, Cieslewicz MJ, Donati C, Medini D, Ward NL, Angiuoli SV, Crabtree J, Jones AL, Durkin AS, Deboy RT, Davidsen TM, Mora M, Scarselli M, Margarit y Ros I, Peterson JD, Hauser CR, Sundaram JP, Nelson WC, Madupu R, Brinkac LM, Dodson RJ, Rosovitz MJ, Sullivan SA, Daugherty SC, Haft DH, Selengut J, Gwinn ML, Zhou L, Zafar N, et al: Genome analysis of multiple pathogenic isolates of Streptococcus agalactiae: implications for the microbial "pan-genome". Proc Natl Acad Sci USA 2005, 102:13950-13955.

50. Larkin MA, Blackshields G, Brown NP, Chenna R, McGettigan PA, McWilliam H, Valentin F, Wallace IM, Wilm A, Lopez R, Thompson JD, Gibson TJ, Higgins DG: Clustal W and Clustal X version 2.0. Bioinformatics 2007, 23:2947-2948.

51. Felsenstein J: PHYLIP: Phylogeny Inference Package, version 3.6. Seattle, WA, USA.: University of Washington 2001.

52. Tatusov RL, Galperin MY, Natale DA, Koonin EV: The COG database: a tool for genome-scale analysis of protein functions and evolution. Nucleic Acids Res 2000, 28:33-36.

53. Lepore LS, Roelvink PR, Granados RR: Enhancin, the granulosis virus protein that facilitates nucleopolyhedrovirus (NPV) infections, is a metalloprotease. J Invertebr Pathol 1996, 68:131-140.

54. Bowen D, Rocheleau TA, Blackburn M, Andreev O, Golubeva E, Bhartia R, ffrench-Constant RH: Insecticidal toxins from the bacterium Photorhabdus luminescens. Science 1998, 280:2129-2132.

55. Brussow H, Canchaya C, Hardt WD: Phages and the evolution of bacterial pathogens: from genomic rearrangements to lysogenic conversion. Microbiol Mol Biol Rev 2004, 68:560-602.

56. Collyn F, Guy L, Marceau M, Simonet M, Roten CA: Describing ancient horizontal gene transfers at the nucleotide and gene levels by comparative pathogenicity island genometrics. Bioinformatics 2006, 22:1072-1079

57. Collyn F, Billault A, Mullet C, Simonet M, Marceau M: YAPI, a new Yersinia pseudotuberculosis pathogenicity island. Infect Immun 2004 72:4784-4790

58. Howard SL, Gaunt MW, Hinds J, Witney AA, Stabler R, Wren BW: Application of comparative phylogenomics to study the evolution of Yersinia enterocolitica and to identify genetic differences relating to pathogenicity. J Bacteriol 2006, 188:3645-3653.
59. Haller JC, Carlson S, Pederson KJ, Pierson DE: A chromosomally encoded type III secretion pathway in Yersinia enterocolitica is important in virulence. Mol Microbiol 2000, 36:1436-1446.

60. Hensel M, Shea JE, Baumler AJ, Gleeson C, Blattner F, Holden DW: Analysis of the boundaries of Salmonella pathogenicity island 2 and the corresponding chromosomal region of Escherichia coli K-12. J Bacteriol 1997, 179:1105-1111.

61. Shea JE, Hensel M, Gleeson C, Holden DW: Identification of a virulence locus encoding a second type III secretion system in Salmonella typhimurium. Proc Natl Acad Sci USA 1996, 93:2593-2597.

62. Thomson NR, Howard S, Wren BW, Prentice MB: Comparative genome analyses of the pathogenic Yersiniae based on the genome sequence of Yersinia enterocolitica strain 8081. Adv Exp Med Biol 2007, 603:2-16.

63. Prentice MB, Cuccui J, Thomson N, Parkhill J, Deery E, Warren MJ: Cobalamin synthesis in Yersinia enterocolitica 8081. Functional aspects of a putative metabolic island. Adv Exp Med Biol 2003, 529:43-46.

64. Roth JR, Lawrence JG, Bobik TA: Cobalamin (coenzyme B12): synthesis and biological significance. Annu Rev Microbiol 1996, 50:137-181.

65. Kofoid E, Rappleye C, Stojiljkovic I, Roth J: The 17-gene ethanolamine (eut) operon of Salmonella typhimurium encodes five homologues of carboxysome shell proteins. J Bacteriol 1999, 181:5317-5329.

66. Maier RJ: Use of molecular hydrogen as an energy substrate by human pathogenic bacteria. Biochem Soc Trans 2005, 33:83-85.

67. Ewing WH, Ross AJ, Brenner DJ, R FG: Yersinia ruckeri sp. nov., the Redmouth (RM) Bacterium. Int J Syst Bacteriol 1978, 28:37-44

68. Sekowska A, Dénervaud V, Ashida H, Michoud K, Haas D, Yokota A, Danchin A: Bacterial variations on the methionine salvage pathway. BMC Microbiol 2004, 4:9

69. Hiller NL, Janto B, Hogg JS, Boissy R, Yu S, Powell E, Keefe R, Ehrlich NE, Shen K, Hayes J, Barbadora K, Klimke W, Dernovoy D, Tatusova T, Parkhill J, Bentley SD, Post JC, Ehrlich GD, Hu FZ: Comparative Genomic Analyses of Seventeen Streptococcus pneumoniae Strains: Insights into the Pneumococcal Supragenome. J Bacteriol 2007, 189:8186-95.

70. Hogg JS, Hu FZ, Janto B, Boissy R, Hayes J, Keefe R, Post JC, Ehrlich GD: Characterization and modeling of the Haemophilus influenzae core and supragenomes based on the complete genomic sequences of $\mathrm{Rd}$ and 12 clinical nontypeable strains. Genome Biol 2007, 8:R103.

71. Mathee K, Narasimhan G, Valdes C, Qiu X, Matewish JM, Koehrsen M, Rokas A, Yandava CN, Engels R, Zeng E, Olavarietta R, Doud M, Smith RS, Montgomery P, White JR, Godfrey PA, Kodira C, Birren B, Galagan JE, Lory S: Dynamics of Pseudomonas aeruginosa genome evolution. Proc Natl Acad SCi USA 2008, 105:3100-3105.

72. Holt K, Parkhill J, Mazzoni C, Roumagnac P, Weill F, Goodhead I, Rance R, Baker S, Maskell D, Wain J, Dolecek C, Achtman M, Dougan G: Highthroughput sequencing provides insights into genome variation and evolution in Salmonella Typhi. Nat Genet 2008, 40:987-93.

73. Simmons S, Dibartolo G, Denef V, Goltsman D, Thelen M, Banfield J, Eisen J: Population Genomic Analysis of Strain Variation in Leptospirillum Group II Bacteria Involved in Acid Mine Drainage Formation. Plos Biol 2008, 6: e177.

74. Rasko D, Rosovitz M, Myers G, Mongodin E, Fricke W, Gajer P, Crabtree J, Sperandio V, Ravel J: The pan-genome structure of Escherichia coli: comparative genomic analysis of E. coli commensal and pathogenic isolates. Journal of Bacteriology 2008, 190:6881-93.

75. Read TD, Peterson SN, Tourasse N, Baillie LW, Paulsen IT, Nelson KE, Tettelin H, Fouts DE, Eisen JA, Gill SR, Holtzapple EK, Okstad OA, Helgason E, Rilstone J, Wu M, Kolonay JF, Beanan MJ, Dodson RJ, Brinkac LM, Gwinn M, DeBoy RT, Madpu R, Daugherty SC, Durkin AS, Haft DH, Nelson WC, Peterson JD, Pop M, Khouri HM, Radune D, et al: The genome sequence of Bacillus anthracis Ames and comparison to closely related bacteria. Nature 2003, 423:81-86

76. Tettelin H, Masignani V, Cieslewicz MJ, Eisen JA, Peterson S, Wessels MR, Paulsen IT, Nelson KE, Margarit I, Read TD, Madoff LC, Wolf AM, Beanan MJ, Brinkac LM, Daugherty SC, DeBoy RT, Durkin AS, Kolonay JF, Madupu R, Lewis MR, Radune D, Fedorova NB, Scanlan D, Khouri H, Mulligan S, Carty HA, Cline RT, Van Aken SE, Gill J, Scarselli M, et al: Complete genome sequence and comparative genomic analysis of an emerging human pathogen, serotype V Streptococcus agalactiae. Proc Natl Acad Sci USA 2002, 99:12391-12396.

77. Sprague LD, Neubauer H: Yersinia aleksiciae sp. nov. Int J Syst Evol Microbiol 2005, 55:831-835. 
78. Sprague LD, Scholz HC, Amann S, Busse HJ, Neubauer H: Yersinia similis sp. nov. Int J Syst Evol Microbiol 2008, 58:952-958.

79. Merhej V, Adekambi T, Pagnier I, Raoult D, Drancourt M: Yersinia massiliensis sp. nov., isolated from fresh water. Int J Syst Evol Microbiol 2008, 58:779-784.

80. Delpino MV, Marchesini MI, Estein SM, Comerci DJ, Cassataro J, Fossati CA, Baldi PC: A bile salt hydrolase of Brucella abortus contributes to the establishment of a successful infection through the oral route in mice. Infect Immun 2007, 75:299-305.

81. Sherlock O, Vejborg RM, Klemm P: The TibA adhesin/invasin from enterotoxigenic Escherichia coli is self recognizing and induces bacterial aggregation and biofilm formation. Infect Immun 2005, 73:1954-1963.

82. Liu B, Pop M: ARDB-Antibiotic Resistance Genes Database. Nucleic Acids Res 2009, 37:D443-447.

83. Antibiotic Resistance Genes Database. http://ardb.cbcb.umd.edu/.

84. Leplae R, Hebrant A, Wodak SJ, Toussaint A: ACLAME: a CLAssification of Mobile genetic Elements. Nucleic Acids Res 2004, 32:D45-49.

85. Kislyuk A, Lomsadze A, Lapidus AL, Borodovsky M: Frameshift detection in prokaryotic genomic sequences. Int J Bioinform Res Appl 2009, 5:458-477.

86. Pop M, Phillippy A, Delcher AL, Salzberg SL: Comparative genome assembly. Brief Bioinform 2004, 5:237-248.

87. Li W, Godzik A: Cd-hit: a fast program for clustering and comparing large sets of protein or nucleotide sequences. Bioinformatics 2006, 22:1658-1659

88. Kurtz S, Phillippy A, Delcher AL, Smoot M, Shumway M, Antonescu C, Salzberg SL: Versatile and open software for comparing large genomes. Genome Biol 2004, 5:R12.

89. Stewart AC, Osborne B, Read TD: DIYA: A bacterial annotation pipeline for any genomics lab. Bioinformatics 2009, 25:962-3.

90. Salzberg SL, Delcher AL, Kasif S, White O: Microbial gene identification using interpolated Markov models. Nucleic Acids Res 1998, 26:544-548.

91. Lowe TM, Eddy SR: tRNAscan-SE: a program for improved detection of transfer RNA genes in genomic sequence. Nucleic Acids Res 1997, 25:955-964.

92. Lagesen K, Hallin P, Rødland EA, Staerfeldt HH, Rognes T, Ussery DW: RNAmmer: consistent and rapid annotation of ribosomal RNA genes. Nucleic Acids Res 2007, 35:3100-3108.

93. Suzek BE, Huang H, McGarvey P, Mazumder R, Wu CH: UniRef: comprehensive and non-redundant UniProt reference clusters. Bioinformatics 2007, 23:1282-1288.

94. Altschul SF, Gish W, Miller W, Myers EW, Lipman DJ: Basic local alignment search tool. J Mol Biol 1990, 215:403-410.

95. Conserved Domain Database(CDD). http://www.ncbi.nlm.nih.gov/sites/ entrez? $\mathrm{db}=\mathrm{cdd}$.

96. Altschul SF, Madden TL, Schaffer AA, Zhang J, Zhang Z, Miller W, Lipman DJ: Gapped BLAST and PSI-BLAST: a new generation of protein database search programs. Nucleic Acids Res 1997, 25:3389-3402.

97. Talavera G, Castresana J: Improvement of phylogenies after removing divergent and ambiguously aligned blocks from protein sequence alignments. Syst Biol 2007, 56:564-577.

98. Read TD, Myers GS, Brunham RC, Nelson WC, Paulsen IT, Heidelberg J, Holtzapple E, Khouri H, Federova NB, Carty HA, Umayam LA, Haft DH, Peterson J, Beanan MJ, White O, Salzberg SL, Hsia RC, McClarty G, Rank RG, Bavoil PM, Fraser CM: Genome sequence of Chlamydophila caviae (Chlamydia psittaci GPIC): examining the role of niche-specific genes in the evolution of the Chlamydiaceae. Nucleic Acids Res 2003, 31:2134-2147.

99. Rasko DA, Myers GS, Ravel J: Visualization of comparative genomic analyses by BLAST score ratio. BMC Bioinformatics 2005, 6:2.

100. Bercovier H, Steigerwalt AG, Guiyoule A, Huntley-Carter G, Brenner DJ: Yersinia aldovae (Formerly Yersinia enterocolitica-Like Group X2): a New Species of Enterobacteriaceae Isolated from Aquatic Ecosystems. Int J Syst Bacteriol 1984, 34:166-172.

101. Wauters $G$, Janssens $M$, Steigerwalt AG, Brenner DJ: Yersinia mollaretii sp. nov. and Yersinia bercovieri sp. nov., Formerly Called Yersinia enterocolitica Biogroups 3A and 3B. Int I Syst Bacteriol 1988, 38:424.

102. Ursing J, Brennert DJ, Bercovier H, Fanning GR, Steigerwalt AG, Brault J, Mollaret HH: Yersinia frederiksenii: A new species of enterobacteriaceae composed of rhamnose-positive strains (formerly called atypical yersinia enterocolitica or Yersinia enterocolitica -Like). Current Microbiology 1980, 4:213-217.
103. Brenner DJ, Bercovier HH, Ursing J, Alonso JM, Steigerwalt AG, Fanning GR, Carter GP, Mollaret HH: Yersinia intermedia: A new species of enterobacteriaceae composed of rhamnose-positive, melibiose-positive, raffinose-positive strains (formerly called Yersinia enterocolitica or Yersinia enterocolitica -like). Current Microbiology 1980, 4:207-212.

104. Bercovier H, Ursing J, Brenner DJ, Steigerwalt AG, Fanning GR, Carter GP, Mollaret HH: Yersinia kristensenii: A new species of enterobacteriaceae composed of sucrose-negative strains (formerly called atypical Yersinia enterocolitica or Yersinia enterocolitica -Like). Current Microbiology 1980, 4:219-224.

105. Aleksic S, Steigerwalt AG, Bockemuehl J: Yersinia rohdei sp. nov. isolated from human and dog feces and surface water. Int J Syst Bacteriol 1987.

106. Carver T, Thomson N, Bleasby A, Berriman M, Parkhill J: DNAPlotter: circular and linear interactive genome visualization. Bioinformatics 2009, 25:119-120.

doi:10.1186/gb-2010-11-1-r

Cite this article as: Chen et al: Genomic characterization of the Yersinia genus. Genome Biology 2010 11:R1.

\section{Submit your next manuscript to BioMed Central and take full advantage of:}

- Convenient online submission

- Thorough peer review

- No space constraints or color figure charges

- Immediate publication on acceptance

- Inclusion in PubMed, CAS, Scopus and Google Scholar

- Research which is freely available for redistribution

Submit your manuscript at www.biomedcentral.com/submit
Ciomed Central 